\title{
On the Seasonal Cycle of the Tropical South Indian Ocean. Part I: Mixed Layer Heat and Salt Budgets
}

\author{
SAULO M. SOARES \\ International Pacific Research Center, School of Ocean and Earth Science and Technology, \\ University of Hawai'i at Mānoa, Honolulu, Hawaii \\ KELVIN J. RICHARDS \\ Department of Oceanography and International Pacific Research Center, School of Ocean and \\ Earth Science and Technology, University of Hawai'i at Mānoa, Honolulu, Hawaii \\ FRANK O. BRYAN \\ National Center for Atmospheric Research, Boulder, Colorado \\ KUNIO YONEYAMA \\ Department of Coupled Ocean-Atmosphere-Land Processes Research, Japan Agency for \\ Marine-Earth Science and Technology, Yokosuka, Kanagawa, Japan
}

(Manuscript received 19 January 2018, in final form 4 January 2019)

\begin{abstract}
Scale interactions in the coupled ocean and atmosphere of the tropics play a crucial role in shaping the climate state and its spatial and temporal variability. The mechanisms driving the seasonal cycles of mixed layer (ML) temperature and salinity in the tropical south Indian Ocean (TSIO) are revisited and quantified using model and observations to form a basis on which to assess the cycle's impact on shorter and longer time scale variability in the region. Budgets of ML heat for the western, central, and eastern TSIO in both model and observations indicate that seasonality in ML temperature is driven by surface heat fluxes in all regions; ocean processes, however, are essential to explain east-west differences in the cycle. In contrast, the salt budgets show that ML salinity in the west and central regions of the TSIO is driven by horizontal advection, with salinity increasing during austral winter mainly due to meridional advection, and freshening during spring-summer due to zonal advection; in the east, no single mechanism appears to dominate ML salinity seasonality. The ML seasonal cycle across the entire region is very much influenced by the basin-scale adjustment that occurs in response to monsoon winds in the eastern side of the basin. Zonal advection, as part of the adjustment process, is the key mechanism responsible for bringing fresher/colder waters from the east to the central and western TSIO during austral spring, leading to a lag in the coldest ML temperatures in the east relative to the west/central TSIO, and effectively coupling the eastern and western TSIO beyond simply Rossby wave dynamics.
\end{abstract}

\section{Introduction}

We examine the mechanisms driving the seasonal cycles of salinity and temperature in the mixed layer (ML) in the tropical southern Indian Ocean (TSIO), with a particular emphasis on the Seychelles-Chagos Thermocline Ridge (SCTR) and the waters off the coast of Sumatra and Java. The SCTR, roughly defined as within $12^{\circ}-4^{\circ} \mathrm{S}$ and $55^{\circ}-85^{\circ} \mathrm{E}$,

Corresponding author: Saulo M. Soares, saulo@hawaii.edu is a zonally elongated area of shallow thermocline (Fig. 1) brought about by the annual-mean wind stress curl pattern (McCreary et al. 1993; Xie et al. 2002). Because the SCTR region is prone to favor strong air-sea interactions, it is believed to be important for the development and evolution of Madden-Julian oscillation (MJO) events (e.g., Vialard et al. 2008, 2009). MJOs in turn influence global precipitation patterns at intraseasonal time scales (Zhang 2005). The open waters off the coast of Sumatra and Java (e.g., eastern box in Fig. 1) 


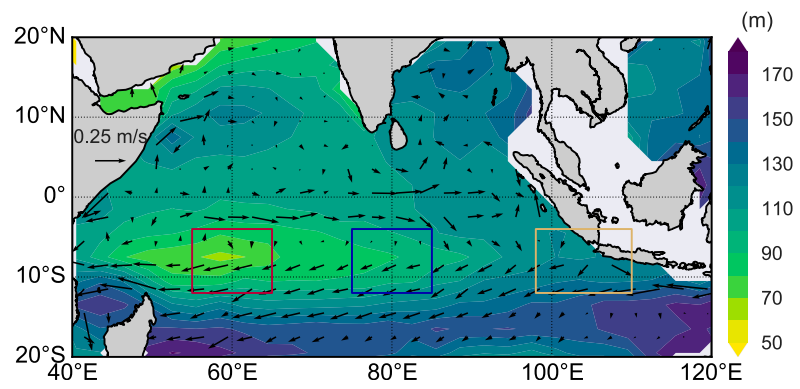

FIG. 1. Map of Argo-derived annual mean depth of the $20^{\circ} \mathrm{C}$ isotherm $\left(\mathrm{z} 20^{\circ} \mathrm{C}\right)$ and surface currents from OSCAR (vectors). The boxes mark the domains used for volume averaging, color-coded according to the legend in Fig. 3a.

are key to understanding the development of Indian Ocean dipole (IOD) events, which impact regional precipitation patterns in the Maritime Continent, Asia, eastern Africa, and Australia at interannual time scales (Saji et al. 1999; Webster et al. 1999; Annamalai et al. 2003; Schott et al. 2009; Halkides and Lee 2009; Ogata et al. 2013; Horii et al. 2013). A complete understanding of the mechanics of the seasonal or annual cycle of the upper ocean in these regions is essential to assess the ocean's role in the two phenomena mentioned above.

Our investigation was initially motivated by the Cooperative Indian Ocean Experiment of Intraseasonal Variability in the Year 2011 (CINDY2011; Yoneyama et al. 2013) observations at $8^{\circ} \mathrm{S}, 80.5^{\circ} \mathrm{E}$, which show the arrival of a colder and much fresher near-surface water mass halfway through November 2011 (Figs. 2b-d). A previous study (Seiki et al. 2013) implicated anomalous advection by the annual downwelling Rossby wave in the abrupt sea surface temperature (SST) cooling. Here, we demonstrate that this fresher/colder water mass has its origins in larger-scale zonal advection processes, which are seasonally locked, and bring waters from off the coast of Sumatra during austral spring in most years as part of the basinwide seasonal cycle of the Indian Ocean.

The essential character of the seasonal cycle in the TSIO is captured by the contrast of warmer, fresher, and shallower mixed layers from November to April (austral spring/summer) versus colder, saltier, and deeper mixed
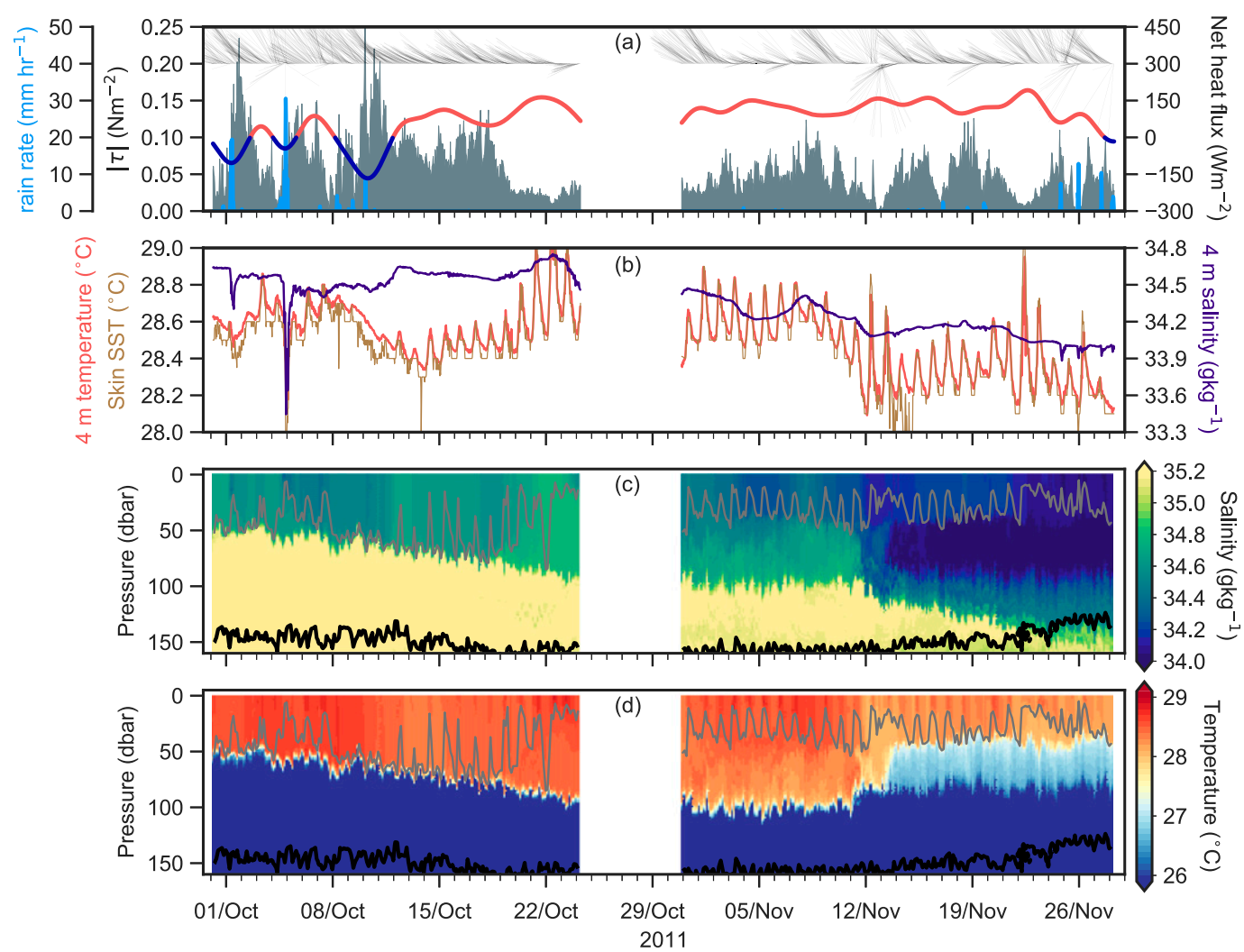

FIG. 2. Surface atmospheric and upper ocean conditions measured from the ship during CINDY2011. (a) Wind stress magnitude (shading) and direction (unit sticks), rain rate (azure bars), and 3-day low-pass net heat flux (thick lines; positive heat flux in red and negative in blue). (b) SST (skin and 4-m intake) and surface salinity (4-m intake). (c),(d) Three-hourly CTD profiles of temperature and salinity, respectively. The gray lines in (c) and (d) denote the mixed layer depth and the black contours denote the depth of the $20^{\circ} \mathrm{C}$ isotherm. There is a gap in the data between 25 and 30 Oct when the ship left the station. 
layers from May to October (austral fall/winter) as shown in Fig. 3 and the top panels of Figs. 4-6. It is clear from these data that seasonality in the SCTR and east TSIO regions evolves differently, despite the influence of the same monsoon regime (hereafter, monsoon means the wind and rain regime of the TSIO and Maritime Continent, not the Indian monsoon regime), and the existence of westward propagating signals (Fig. 7) implies that the two regions are also connected, and therefore should be studied together.

A few past studies have examined the balances and mechanisms driving the seasonal cycle in these regions individually. In the SCTR, an earlier study (Zhou et al. 2008) found that seasonal temperatures are mostly driven by surface fluxes. In subsequent studies, Halkides and Lee (2011) instead suggested that ocean vertical mixing was equally important, while meridional advection was found to be important by Yokoi et al. (2012). These studies analyzed heat budgets derived from ocean general circulation models (OGCMs) and show some agreement with the observation-based heat balance of Foltz et al. (2010), except with regard to the seasonality of vertical processes and that surface heat fluxes lead to warming year round in the observations. In the eastern end of the TSIO, off Sumatra and Java, the seasonal heat budget is believed to be dominated by the surface fluxes as well (Du et al. 2005; Halkides and Lee 2009). Horizontal advection was found to generally warm the eastern TSIO during most of the year (Halkides and Lee 2009), despite the fact that north and westward currents prevail during the southeast trade winds and waters to the south and east are colder.

Halkides and Lee (2011) also investigated the SCTR seasonal salinity balance, which was found to be dominated by meridional advection. In contrast, Da-Allada et al. (2015), analyzing gridded observational products, suggest the dominance of surface freshwater fluxes in the SCTR. We note that the studies above emphasize meridional advection as dominant over zonal advection. Surprisingly, despite the importance of salinity to the upper ocean density structure, no study to our knowledge has provided a closed salinity budget at seasonal scales in the eastern TSIO.

As seen above, the literature on ML seasonality in the TSIO is scattered and often conflicting, with studies using distinct datasets and methodologies and focusing on different regions. We further point out that none of the aforementioned studies evaluates the role of eddy fluxes of heat and salt that could rectify into monthly means. The overarching goal of our investigation is to present a comprehensive and unified picture of the processes driving the seasonal cycles of temperature and salinity across the Southern Hemispheric tropical Indian Ocean. This enables us to identify austral spring as a pivotal time
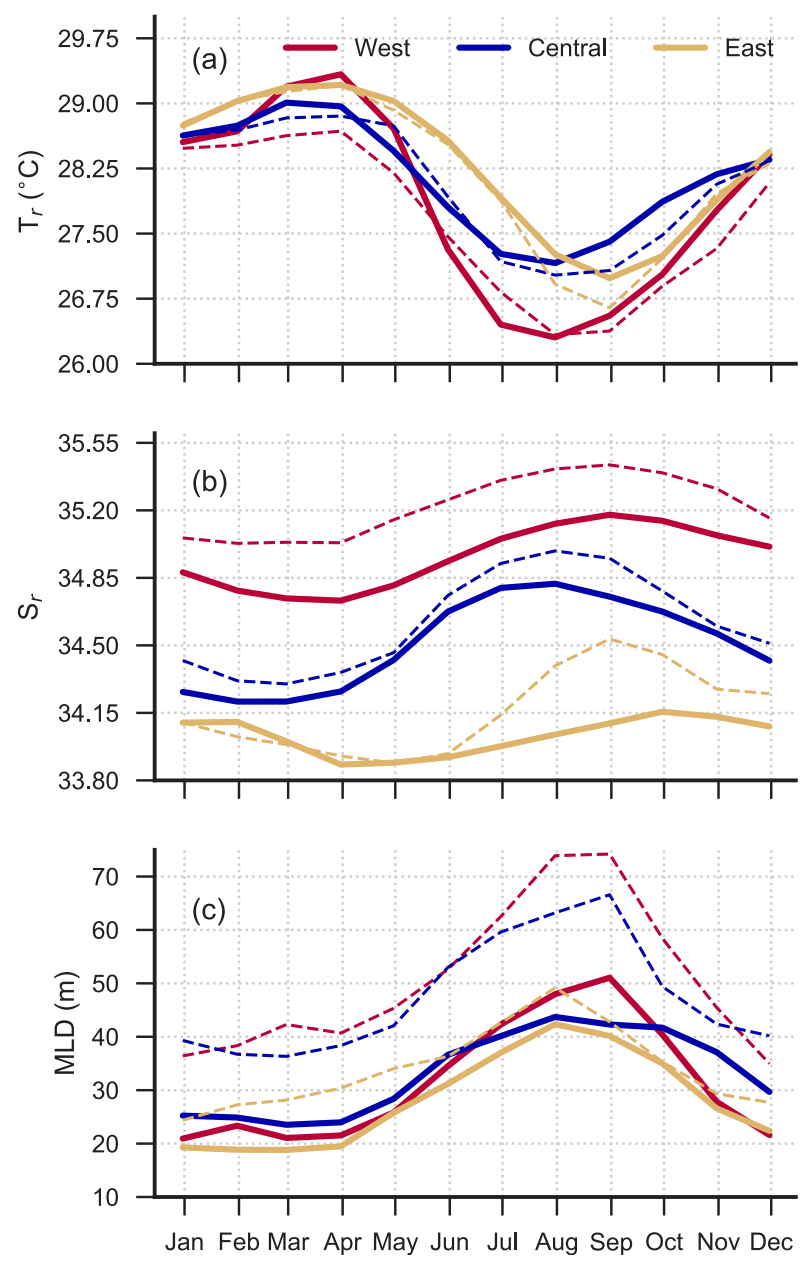

FIG. 3. Seasonal cycles of domain volume averaged mixed layer properties: (a) temperature, (b) salinity, and (c) depth. Thick full lines indicate Argo-derived quantities, while thin dashed lines indicate POP-derived quantities. Domains used for averaging are shown in Fig. 1.

to study many features of the seasonal cycle across the basin to help us understand variability at higher and lower frequency. The investigation here is carried out by calculating ML salt and heat budgets in a model and in gridded observational products. To determine the origins of water masses and connect the seasonal-scale processes to the CINDY2011 observations, we use an ocean reanalysis flow field to track particles alongside their temperature and salinity history.

This paper is organized as follows: in section 2 we describe the model, observational, and ocean reanalysis datasets used in the investigation, while section 3 compares the seasonal cycle features between the model and observations. Section 4 presents the formulation and algorithm of the ML heat and salt budgets. The results for the seasonal monthly-mean budgets are detailed and discussed in section 5. Section 6 deals with the results of 
(a) ARGO MLT Nov-Apr

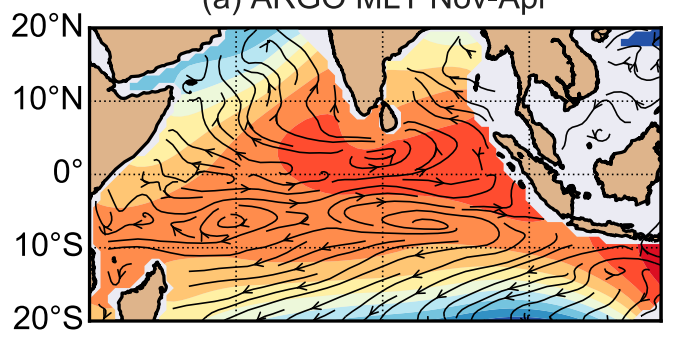

(c) POP MLT Nov-Apr

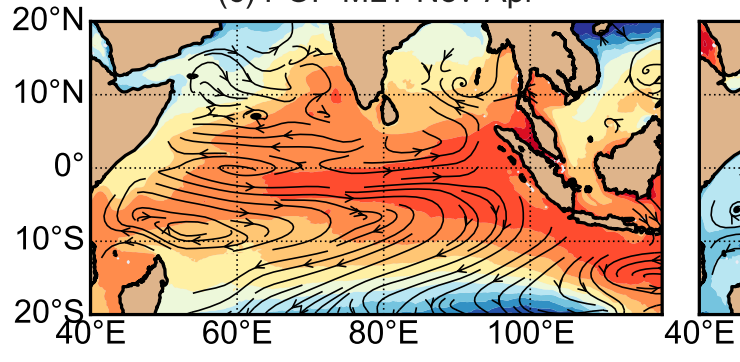

(b) ARGO MLT May-Oct

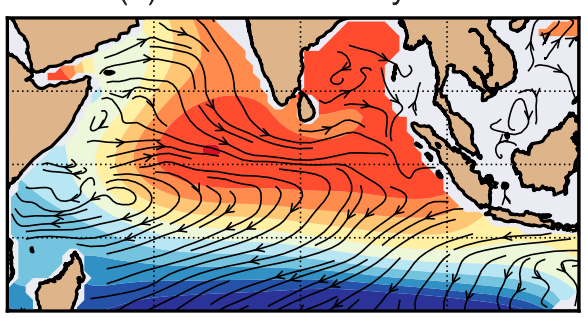

(d) POP MLT May-Oct

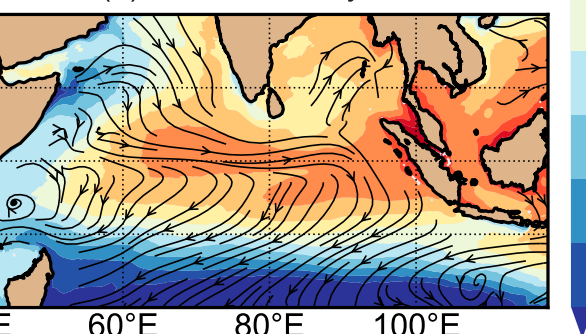

$100^{\circ} \mathrm{E}$
${ }^{\circ} \mathrm{C}$

30

29

26

FIG. 4. Maps of mixed layer temperature averaged for austral (left) spring/summer and (right) fall/winter derived from (top) Argo vs (bottom) POP. Streamlines denote the associated circulation (using OSCAR as current observations).

particle tracking that help connect the broader budget results to the CINDY2011 observations. Section 7 summarizes our main findings and discusses some of their broader implications.

\section{Data}

\section{a. Model}

To fully describe the seasonal budgets of ML temperature and salinity along the TSIO, we use output from a numerical global OGCM. The model we use is the Parallel Ocean Program version 2 (POP), the ocean component of the Community Earth System Models (Smith et al. 2010). POP is a $z$-level vertical coordinate model (using 62 levels) configured on a global tripole $\mathrm{B}$ grid. The horizontal resolution of the model is $0.1^{\circ}$ and the vertical resolution is $10 \mathrm{~m}$ in the upper $160 \mathrm{~m}$, increasing to $250 \mathrm{~m}$ in the deep ocean. The surface ML and boundary layer dynamics and interior diapycnal mixing are handled by the $K$-profile parameterization (KPP; Large et al. 1994). Subgrid lateral mixing is parameterized with a biharmonic operator with hyperviscosity and diffusivity scaled by the cube of the local grid spacing.

In this study, we use climatological, monthly averaged three-dimensional fields of temperature $T$, salinity $S$, and zonal, meridional, and vertical components of velocity ( $u, v$, and $w$, respectively), as well as all monthly averaged three-dimensional fluxes (including surface and eddy) and tendencies of heat and salt from the output of a single nondated simulation called the POP normal-year forcing experiment. Henceforth we reference these data simply as the POP model. The normal-year forcing constitutes a synthetic, repeated year of meteorological forcing data at 6-h intervals constructed from the Coordinated Ocean-Ice Reference Experiment (CORE), which is essentially an adjusted product blending reanalysis and remote sensing atmospheric data for the 1948-2009 period (Large and Yeager 2004, 2009). The air-sea fluxes of momentum, heat, and freshwater are then computed at the same interval by combining the CORE meteorological information with the model's predicted SST and velocity (Bryan and Bachman 2015). The monthly averaged state variables and all fluxes required to recover the exact term balances are calculated from 5-day outputs of the last 5 years of a 20 -yr-long integration. We then compute ML and domain averages of all quantities offline, as described in section 4 using the ML definition outlined below. More information on the model physics and configuration can be found in Bryan and Bachman (2015).

\section{b. Gridded observational products}

Our study makes use of gridded observational products 1) to evaluate the simulated seasonal cycles of ML properties and 2) to compute tendency, horizontal advective, and surface forcing terms in the heat and salt budgets at seasonal time scale. For ocean ML properties (temperature, salinity, and ML depth, hereinafter 
(a) ARGO MLS Nov-Apr

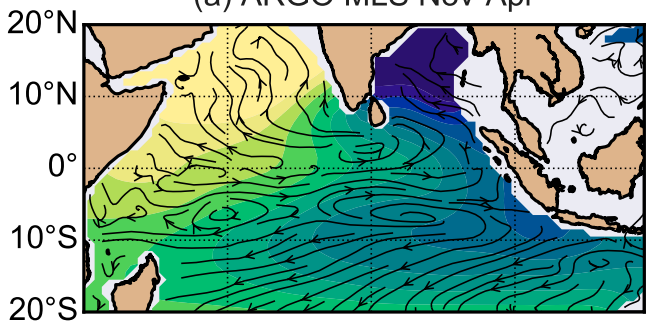

(c) POP MLS Nov-Apr

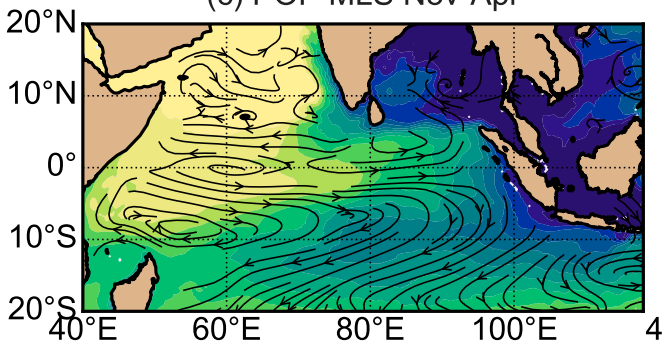

(b) ARGO MLS May-Oct

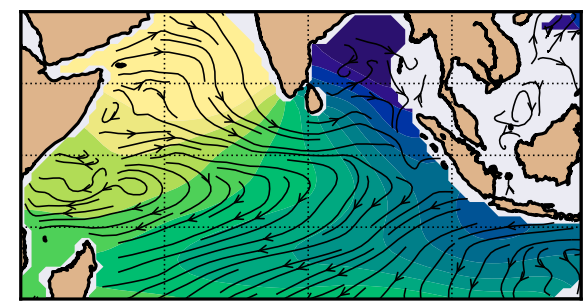

(d) POP MLS May-Oct

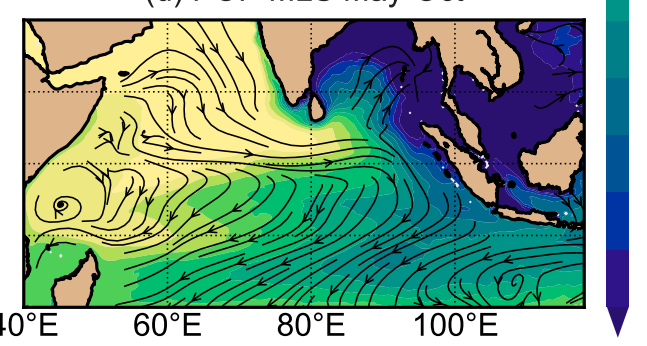

$\mathrm{g} / \mathrm{kg}$

35.5

35.0

34.5

34.0

33.5

FIG. 5. As in Fig. 4, but for mixed layer salinity.

referred to as MLT, MLS, and MLD) we use Argo data (Argo 2018) that have been objectively interpolated into a $1^{\circ} \times 1^{\circ}$ grid and monthly averaged (Lebedev et al. 2010a, b). The criterion for MLD used in this product is the depth at which density increases by an amount equivalent to a temperature drop of $0.2^{\circ} \mathrm{C}$ from the density value at $10 \mathrm{~m}$. We therefore use this same criterion of ML definition to form model ML properties and budgets.

Similarly to previous studies (e.g., Da-Allada et al. 2015), we assume that OSCAR currents (Bonjean and Lagerloef 2002; Earth Space Research 2009) represent the depth averaged ML currents, and use them to examine the circulation patterns and compute the horizontal advection terms in the observed temperature and salinity budgets. OSCAR currents are originally available as 5-day means on a $1 / 3^{\circ}$ resolution grid. We then calculate monthly means and use a conservative scheme to regrid the OSCAR data onto the Argo ML product $1^{\circ} \times 1^{\circ}$ grid.

To estimate the sampling errors for the Argo ML product (see appendix A) we turn to a $3^{\circ} \times 3^{\circ}$ horizontally binned version of the monthly averaged Argo ML product. A similar resolution Argo product of climatologically averaged isopycnals (Lebedev et al. 2010a,b) is used to plot the depth of the thermocline as the $20^{\circ} \mathrm{C}$ isotherm depth. (a) ARGO MLD Nov-Apr

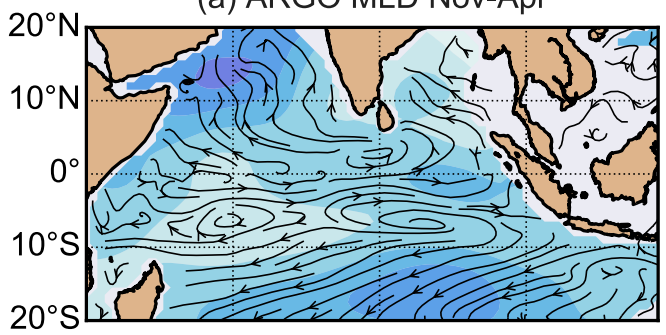

(c) POP MLD Nov-Apr

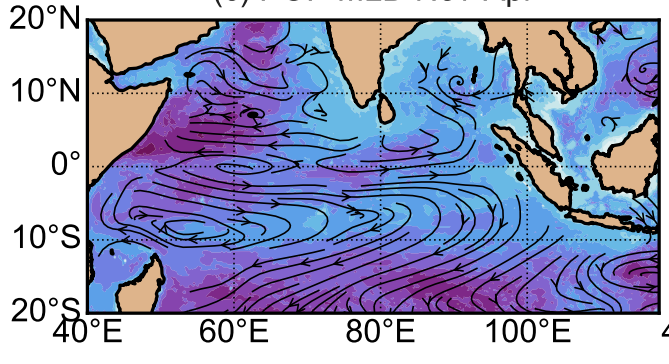

(b) ARGO MLD May-Oct

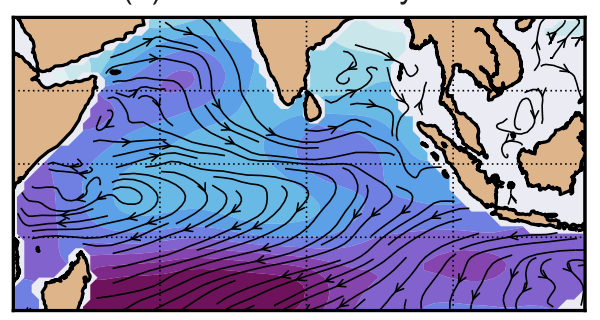

(d) POP MLD May-Oct

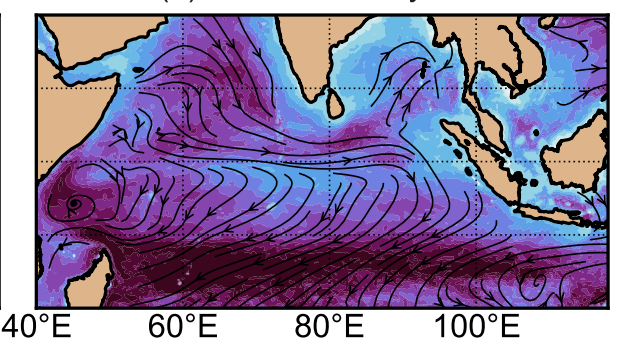

40

30

FIG. 6. As in Fig. 4, but for mixed layer depth. 

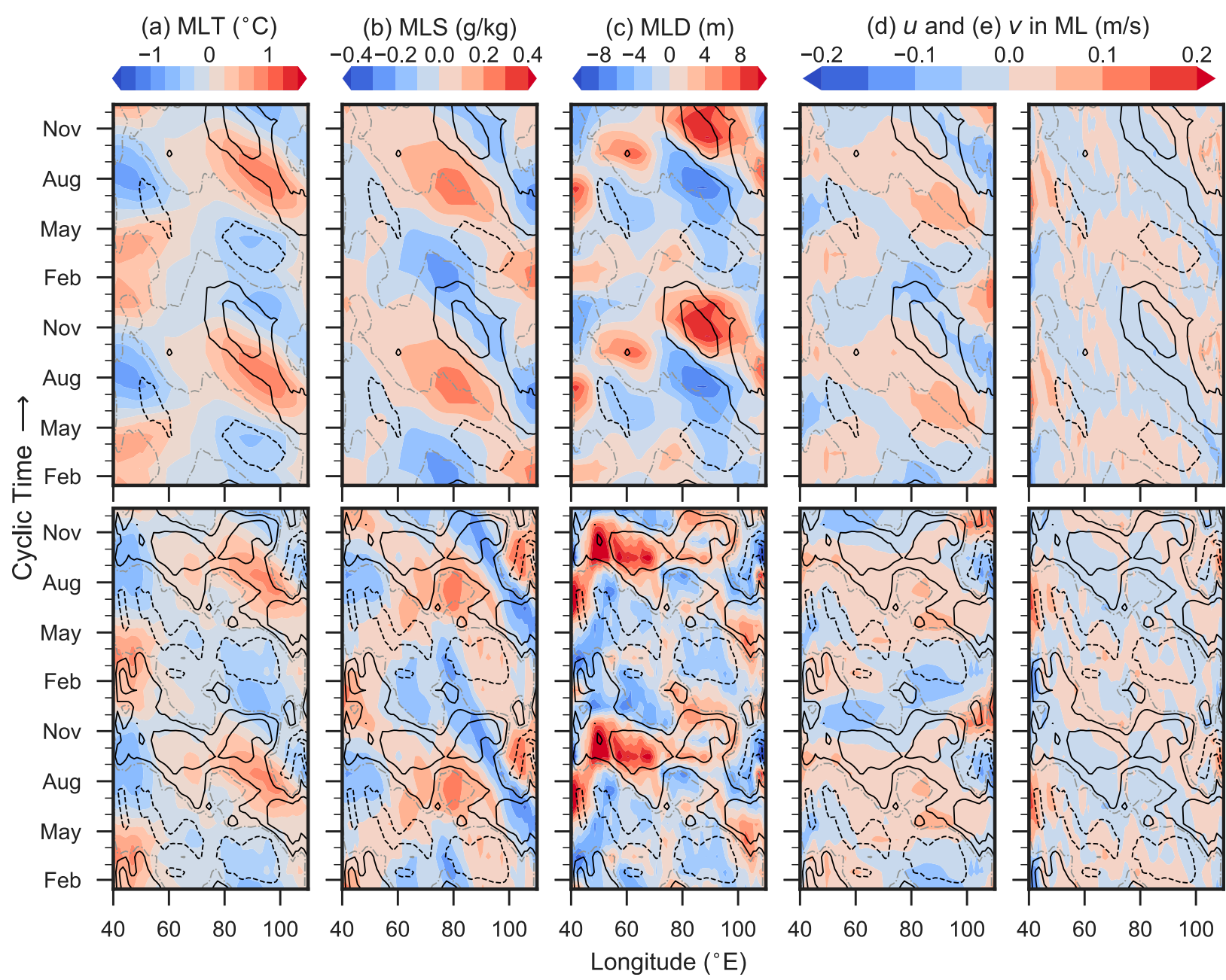

FIG. 7. Hovmöller diagrams of zonal and seasonal anomalies in the $12^{\circ}-4^{\circ} \mathrm{S}$ band for (top) observations and (bottom) POP. The thin black contours show sea surface height anomalies at \pm 5 and $\pm 10 \mathrm{~cm}$ ( \pm 3 and $\pm 6 \mathrm{~cm}$ for POP) levels (filled positive; dashed negative; gray dash-dotted the zero contour). Shading shows anomalies in mixed layer (a) temperature, (b) salinity, (c) depth, (d) zonal component of velocity, and (e) meridional component of velocity.

For solar shortwave radiation, latent, sensible, and longwave radiation heat fluxes, as well as evaporation at the air-sea interface, we use the OAFlux dataset (Yu et al. 2008, accessed via the APDRC). For precipitation, we use the Tropical Rainfall Measuring Mission (TRMM) 3B43 product version 7 (Huffman et al. 2007; TRMM 2011) available at $0.25^{\circ}$ resolution. Both these datasets are comprised of monthly averaged quantities covering the $2005-16$ period. OAFlux is available in the same $1^{\circ} \times 1^{\circ}$ grid as Argo. All other surface data are regridded onto the Argo grid.

All gridded products described in here comprise 12 years of data covering the same period of 2005 to 2016 . Note that OAFlux depends on shortwave and longwave radiation data from ISCCP (Rossow and Schiffer 1999). The record of ISCCP data, however, ends in 2009. Hence, we turn to the ERA-Interim reanalysis (ERA-I; Dee et al. 2011) to address the heat budget in years 2010 to 2016. Monthly averages are formed from the $12 \mathrm{~h}$ accumulated ERA-I net shortwave and longwave radiation surface flux fields. We compare the ERA-I radiative flux components to those of OAFlux for their overlapping period (2005-09) and, despite some differences and biases, find that both datasets are largely consistent. We correct some of the obvious bias issues in ERA-I using linear fit parameters obtained from the period when OAFlux/ISCCP and ERA-I overlap (see appendix A).

\section{c. Ancillary observations and ocean reanalysis products}

We examine in situ data from CINDY2011 to connect the seasonal-scale processes to local conditions observed at $8^{\circ} \mathrm{S}, 80.5^{\circ} \mathrm{E}$ in the central TSIO. Here, we focus on upper ocean measurements of $T, S$, and meteorological 
variables (winds, air temperature, rain rate, and downward shortwave and longwave radiation) from $30 \mathrm{Sep}-$ tember through 28 November 2011 taken aboard the R/V Mirai. Air-sea fluxes of heat and wind stress are calculated with the COARE 3.0 bulk flux algorithm (Fairall et al. 2003) using 30-min averages of high-frequency surface ocean and meteorological data. We also use 3hourly, 1-dB resolution CTD $T / S$ data. From the CTD data, we estimate a MLD corresponding to a density difference of $0.03 \mathrm{~kg} \mathrm{~m}^{-3}$ from the surface value, which yields a good correspondence with the elevated levels of turbulence measured during this period (not shown).

To estimate some of the random errors and biases in the gridded surface flux products, we use flux estimates based on measurements from the Research Moored Array for African-Asian-Australian Monsoon Analysis and Prediction (RAMA) buoys (McPhaden et al. 2009) and the COARE3.0 algorithm. A total of 13 buoys are available within the TSIO area, providing monthly means of surface latent, sensible, and shortwave radiation, evaporation, and precipitation for most of the 2005-16 period to make direct comparisons to the products. Longwave radiation data, however, have limited availability. To assess the model eddy kinetic energy (EKE) levels, we turn to the Global Drifter Program (GDP) climatology on near-surface currents (Laurindo et al. 2017) and specifically to its data on current variance (annual mean). The RAMA and GDP datasets are available online [see NOAA (2016) and NOAA (2018), respectively].

Finally, we look to the MERCATOR global ocean analysis product (http://cmems-resources.cls.fr/documents/ PUM/CMEMS-GLO-PUM-001-024.pdf) to provide high spatial and temporal resolution near-surface currents (taken to be upper 20-m averages) during 2011. The MERCATOR output of the global assimilation system is available as daily averages at a $1 / 12^{\circ}$ horizontal resolution grid with vertical resolution varying around $1 \mathrm{~m}$ in the upper $30 \mathrm{~m}$. The high-resolution currents are used to perform Lagrangian tracking of particles (virtual floats). A brief description of the tracking algorithm is contained in appendix B. Near-surface $T / S$ values extracted from MERCATOR are recorded along the many particle's trajectories.

\section{Model versus observations comparison}

The overall skill of POP in simulating the spatial patterns of the annual mean and seasonal cycle of the ML in the TSIO is summarized by the Taylor diagrams shown in Fig. 8. POP simulates very accurately the annual mean MLT and MLS pattern. While the model annual mean MLD pattern correlates well with the observations, it shows more variability (Fig. 8a). POP is
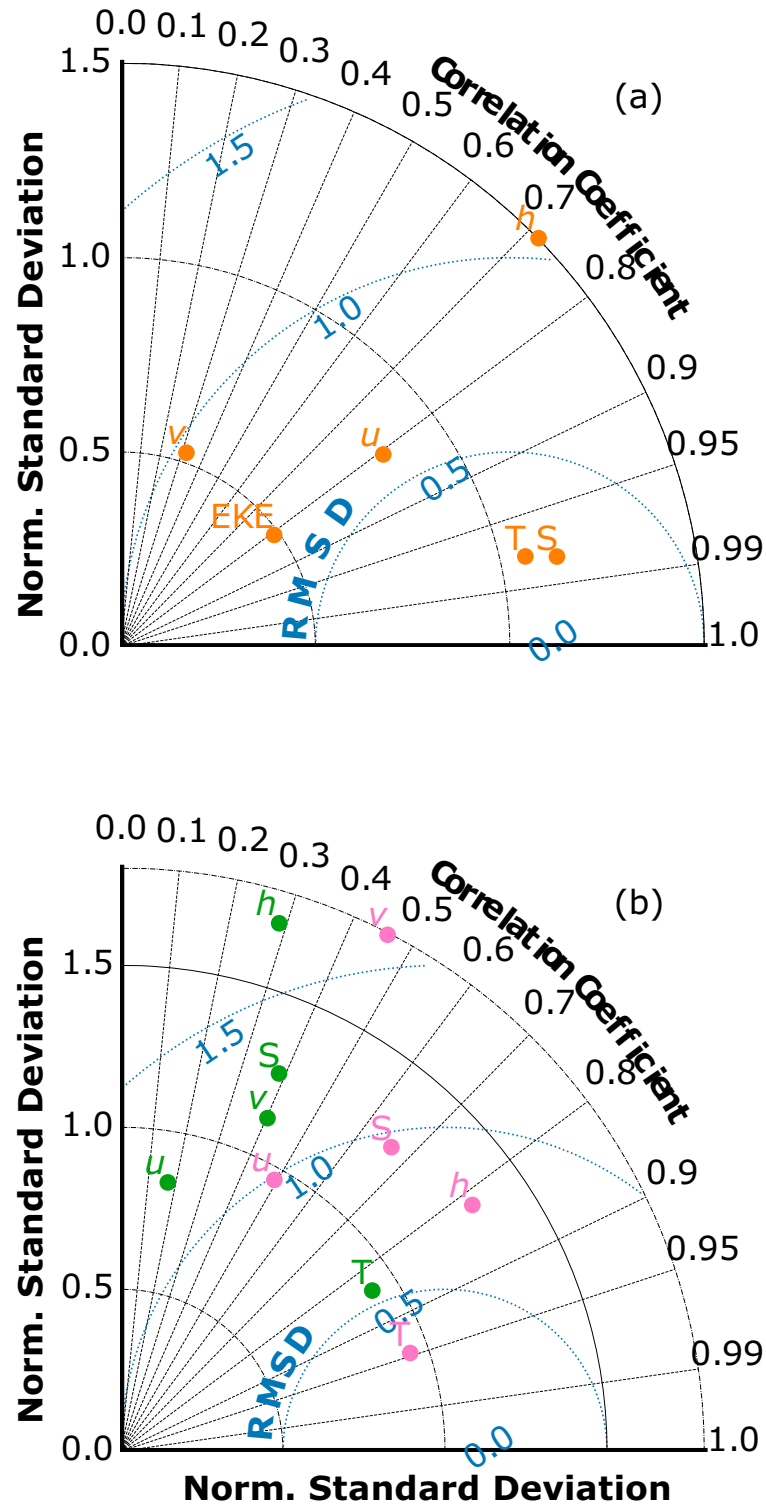

FIG. 8. Taylor diagrams comparing several mixed layer/surface POP quantities to observations for (a) annual mean spatial pattern and (b) seasonal cycle amplitude (magenta) and phase (green) spatial patterns. The diagram is normalized by the observations, and model-observation differences taken in the area between $15^{\circ} \mathrm{S}-0^{\circ}$ and $50^{\circ}-115^{\circ} \mathrm{E}$, after conservative regridding onto the Argo grid. The seasonal cycle's amplitude and phase are obtained following the method of Stine and Huybers (2012).

also skillful in reproducing the pattern of the persistent surface zonal currents like the South Equatorial Current (SEC; $u$ in Fig. 1), but shows poor skill for the meridional component of velocity (Fig. 8a).

The model shows high skill in simulating the spatial patterns of the amplitude and phase of the seasonal cycle of MLT (Fig. 8b). The amplitude (phase) of the 
POP MLS cycle correlates (poorly correlates) with observations, but systematically overestimates both amplitude and phase spatial variability (Fig. 8b). The pattern of the MLD cycle amplitude is well reproduced (high correlations) by the model albeit also with excessive spatial variability; its phase, however, is not at all (Fig. 8b). Likewise, POP shows skill for the patterns of the seasonal amplitude of $u$ but not for its phase; for the cycle of $v$, POP shows general poor skill (cf. Fig. 8b).

The Taylor diagrams imply that POP is not very skillful in reproducing the spatial pattern of the phase of the seasonal cycle (all above skill assessments are qualitatively insensitive to exact domain specifications). Domain volume-averaged quantities (Fig. 3), however, strongly indicate that the cycle's amplitude and phase are well resolved in the regions of interest, with the exception of east TSIO salinity where the amplitude is overestimated. Most importantly, POP reproduces the lag in the coldest MLT of the east TSIO. Here, we give much attention to this lag, as it has been overlooked in the literature and is tightly connected with the MLS freshening in the central TSIO.

Biases in the model are obvious. The model MLD is biased deep by $\sim 15 \mathrm{~m}$, and more so toward the west TSIO (e.g., Fig. 3c). POP is also systematically colder, especially during summer in the west TSIO, and saltier. It is unclear exactly how much of the cold and salty bias is due to the biased-deep MLDs.

Since the maps of differences in phase are noisy, and to try and better understand the model's skill, we detail the large-scale spatial patterns of seasonal ML properties and associated circulation, contrasting maps for November-April and May-October averages between the observations and POP (Figs. 4-6). These averaging periods bracket the peaks (around March/April) and troughs (circa August/September) of ML properties along the TSIO and the respective warming/freshening and cooling/increase-in-salinity phases (Fig. 3).

In terms of the MLD, the POP does a reasonable job in capturing the year-round shallower MLs associated with the SCTR and the larger-scale distribution of MLD (Fig. 6). The model also qualitatively reproduces the deeper MLD in the Arabian Sea and the relatively shallower MLDs of the Bay of Bengal, with slightly better agreement between model and observation during winter than during summer.

The model reproduces the large-scale spatial distribution of MLT in both seasons reasonably well, including the wintertime upwelling off the coast of Somalia and cold tongue south of Sri Lanka, the summertime warmer equatorial east Indian Ocean, and the colder southeastern TSIO (Figs. 4a,c). During summer, POP shows MLTs in excess of $29^{\circ} \mathrm{C}$ south of the equator and toward the east, which are displaced northward in the observations (Figs. 4a,c). In the TSIO, there appears to be a weaker meridional gradient of MLT north of $10^{\circ} \mathrm{S}$ (Figs. 4b,c).

The large-scale spatial distribution of model MLS in both seasons (Fig. 5) agrees reasonably well with observations, simulating both the equatorial tongue of salty water and the TSIO tongue of low salinity water during November-April, as well as the generally fresher bay of Bengal and saltier Arabian Sea. POP also captures the retreat of the fresher tongue during winter with the accompanying southeastward spread of high-salinity water from the Arabian Sea into the SCTR western dome (Fig. 5b). Along the south of Sri Lanka, however, the model exaggerates this expansion, introducing an unrealistically large meridional gradient (Fig. 5c).

Perhaps the starkest contrast is between POP's basinwide circulation and that of OSCAR during November-April (see the streamlines in Figs. 4a,c), while the May-October period sees better agreement (cf. Figs. 4b,d). The SCTR cyclonic gyre (its westernmost dome) in POP is displaced to the southwest on both seasons, and the currents within the TSIO are oriented much more north-south during summer than in OSCAR.

The annual downwelling Rossby wave is a prominent signal in the TSIO (Périgaud and Delecluse 1992; Schott et al. 2009). We examine zonal and seasonal anomalies in ML variables in relation to thermocline displacements [indicated by sea surface height (SSH)] to highlight the many westward signals (Fig. 7). The Rossby wave passage (marked by the positive SSH) leaves a strong signature in MLT in the central/eastern TSIO, particularly around $90^{\circ} \mathrm{E}$ (Fig. 7a). The Rossby wave passage, however, does not coincide with MLT anomalies in other longitudes and or with the strongest anomalies in MLS anywhere along the TSIO, implying that other dynamics are more important. POP adequately simulates the Rossby wave (e.g., its phase speed and zonal extent, as inferred from SSH) and the key westward signals in ML variables (Fig. 7), although with varying degrees of skill (e.g., poorer skill for MLS). An exception is the westward anomalies in the zonal component of the current that occur in the wake of the Rossby wave, a consequence of the weaker, narrower, and southward displaced spring jets (see section 6a) in the model.

\section{Mixed layer budget formulation}

The month-to-month evolution of the model ML salt and heat budgets is given by 


$$
\begin{aligned}
\left\langle\overline{\left.\frac{\partial T}{\partial t}\right\rangle=}\right. & \frac{1}{\bar{h}}\left[\overline{\mathrm{SF}}-\overline{\left.\kappa_{z}\left(\frac{\partial T}{\partial z}-\Gamma\right)\right|_{z=-\bar{h}}}\right]-\langle\nabla \cdot(\overline{\mathbf{v}} \bar{T})\rangle \\
& -\left\langle\nabla \cdot\left(\mathbf{v}^{\prime} T^{\prime}\right)\right\rangle-\left\langle\overline{A_{T} \nabla_{H}^{4} T}\right\rangle,
\end{aligned}
$$

where $T$ stands for tracer (temperature or salinity), $\mathbf{v}$ is the three-dimensional current vector, $\kappa_{z}$ is the vertical diffusivity and $\kappa_{z} \Gamma$ the KPP countergradient flux (Large et al. 1994), $A_{T}$ is the horizontal hyperdiffusivity coefficient, and the subscript $H$ denotes the horizontal component. The overbars denote monthly mean fields and the angle brackets denote averaging in a ML of depth $\bar{h}(x, y, t)$; that is, \langle\rangle$=\bar{h}^{-1} \int_{z=-h}^{z=0} d z$. The prime quantities represent eddying motions with time scales of less than 30 days.

In (1), the $\overline{\mathrm{SF}}$ term represents net surface forcing, which for temperature and salinity are respectively given by

$$
\overline{\mathrm{SF}}=\left\{\begin{array}{cc}
\frac{1}{\rho C_{p}}\left(\overline{q_{0}-q_{-h}+Q}\right), & \text { if } T \text { is temperature } \\
S_{\mathrm{ref}}(\overline{E-P}), & \text { if } T \text { is salinity }
\end{array}\right\},
$$

where $\rho$ is the density of seawater and $C_{p}$ its specific heat, $q_{0}$ is the shortwave radiation $\left(Q_{\mathrm{sw}}\right)$ at the surface and $q_{-\bar{h}}$ is the penetrative shortwave radiation, $Q$ is the sum of outgoing longwave radiation, latent, and sensible surface heat fluxes, $E$ is evaporation, $P$ is precipitation, and $S_{\text {ref }}=34.7$ is a constant reference salinity used for conversion of freshwater flux to virtual salinity flux. The next four terms in (1) represent, respectively, the vertical diffusion (i.e., turbulent mixing), the divergence of the mean advective tracer flux, the divergence of eddy advective tracer flux (i.e., rectifying role of eddy fluxes), and the horizontal diffusion of the tracer.

We volume average (1) over a large horizontal domain, as in \{\}$=V_{D}^{-1} \iint_{x, y} \bar{h} d y d x$, where $V_{D}(t)$ is the total volume of the domain. Since the model outputs all the above required time-averaged fluxes, tendencies, and mean fields, we readily obtain the eddy fluxes and we comfortably perform all integrations offline such that (1) and its volume-averaged version close exactly. To look at individual components of advection in an unambiguous manner (i.e., independent of the definition of zero tracer value; see Lee et al. 2004), we make use of a volume-weighted average reference value, $T_{r} \equiv\{\bar{T}\}$ and subtract $\overline{\mathbf{v}} T_{r}$ from the monthly-mean advective fluxes prior to the integrations.

The form of (1) is not suitable for our gridded monthly and ML averaged observations, as we do not have access to averaged fluxes and tendencies like we do for POP. Following Moisan and Niiler (1998), we obtain a budget equation for ML quantities whose mean advection is relative (to a constant reference tracer value) flux form rather than gradient form:

$$
\begin{aligned}
\left\{\frac{\partial\langle\bar{T}\rangle}{\partial t}\right\}= & \left\{\frac{\overline{\mathrm{SF}}}{\bar{h}}\right\}-\left\{\frac{\partial\langle\bar{u}\rangle\left(\langle\bar{T}\rangle-T_{r}\right)}{\partial x}\right\}-\left\{\frac{\partial\langle\bar{v}\rangle\left(\langle\bar{T}\rangle-T_{r}\right)}{\partial y}\right\}-\left\{\frac{\left(\langle\bar{T}\rangle-T_{r}\right)}{\bar{h}}\langle\overline{\mathbf{u}}\rangle \cdot \nabla \bar{h}\right\} \\
& -\left\{\frac{1}{\bar{h}}\left[\nabla \cdot\left(\int_{-\bar{h}}^{0} \widehat{\overline{\mathbf{u}}} \hat{\bar{T}}\right) d z+\left(\langle\bar{T}\rangle-T_{-\bar{h}}\right) \frac{\partial \bar{h}}{\partial t}+\left(T_{r}-T_{-\bar{h}}\right)\left(\overline{\mathbf{u}}_{-\bar{h}} \cdot \nabla \bar{h}+\bar{w}_{-\bar{h}}\right)\right]\right\} .
\end{aligned}
$$

In the above, $\langle\bar{T}\rangle$ represents Argo-derived monthlymean ML depth-averaged tracer quantities; $\langle\bar{u}\rangle$ and $\langle\bar{v}\rangle$ are the OSCAR monthly mean surface zonal and meridional currents, respectively. The $\overline{\mathrm{SF}}$ term above is practically identical to (2): for model penetrative heating at $z=-\bar{h}$ we assume Argo floats sample a Jerlov water type $1 \mathrm{~A}$ (no sensitivity to similar open-water types was found), while no reference salinity $S_{\text {ref }}$ is used for the surface freshwater flux. Instead, we use the corresponding $\bar{S}$. Also, net fluxes are obtained from monthly averaged fluxes. These fluxes are distributed evenly in the Argo monthly mean MLD ( $\bar{h}$ above).

We are able to compute the first five terms in (3). The tendency term in (3) is computed with central differences while the advective flux terms are evaluated from staggered, interpolated values at the boundaries of the Argo $T$ grid cells. The fourth term on the right-hand side (RHS) of (3) is mostly negligible. Any unbalanced remainder in (3) is referred to as the residual $R$. Each term is calculated for every month in the time series and a seasonal composite for every calendar month is calculated by averaging over the 12 years. The divergences of horizontal fluxes that depart from the vertical mean [fifth term on the RHS of (3)] and the subsurface terms [entrainment, lateral induction, and vertical advection, the last three terms on the RHS of (3)], as well as the rectified impact of eddy/turbulent fluxes (not explicitly written), are unresolved processes that, together with errors in the observations, contribute to $R$.

Entrainment/detrainment and lateral induction along a sloping ML are important processes/terms often mentioned 
in ML budget studies (e.g., Moisan and Niiler 1998; Kim et al. 2006, 2007). Unlike in (3), these terms are bundled and not explicitly separated in (1); in (1), lateral induction is part of the horizontal advection terms and entrainment/ detrainment is part of the tendency term; see (4) below. The reason for not separating them out is that calculation of these terms is nontrivial (e.g., Kim et al. 2006), especially when done offline from time-averaged data (whether observed or model-based), which prevents an exact (to numerical precision) closure of budgets.

Given its relevance in interpreting ML budgets, and because we want to compare the tendencies in (1) with those from the observations [see (3)], we compute estimates of entrainment/detrainment from the model monthly mean output using

$$
\left\{\left\langle\frac{\partial \bar{T}}{\partial t}\right\rangle\right\}=\left\{\frac{\partial\langle\bar{T}\rangle}{\partial t}\right\}+\left\{\bar{h}^{-1} \frac{\partial \bar{h}}{\partial t}\left(\langle\bar{T}\rangle-\overline{T_{-\bar{h}}}\right)\right\},
$$

where $T_{-\bar{h}}$ is the tracer value of the water to be entrained/detrained. First, we use the scheme proposed by Kim et al. (2006) to calculate the second term on the RHS of (4). Second, we use central finite differences on the monthly averaged output to evaluate the tendencies in the LHS and RHS of (4) and take the difference between the two. We average both methods to provide a best estimate for the entrainment/detrainment in the model. Bounds for the entrainment estimate are given by contrasting the result obtained using the Kim scheme with that obtained by taking the difference between tendencies on the LHS and on the RHS of (4). Again, because these terms are calculated from time-averaged state variables, we cannot close the budget exactly as in (1); however, adding this entrainment/detrainment estimate to the tendency in (1) should produce a reasonable approximation of the tendency of the ML averaged tracer.

\section{Seasonal ML budgets}

We examine the seasonal budgets of MLS and MLT in three domains along the TSIO (shown in Fig. 1a), respectively representing, from west to east, the western sector of the SCTR (west box), the central Indian Ocean (eastern sector of the SCTR) (central box), and the waters offshore Sumatra and Java (east box). Equations (1) and (3), as well as the reference values $T_{r}$ and $S_{r}$, are evaluated for these domains. The choice of these domains follows from the literature to allow us to gauge the extent to which domain configuration impacted comparisons among past studies. We focus first on the model budgets and consider the relative contribution of the various terms and processes driving MLS and MLT.
These are then compared with the observation-based budgets.

\section{a. Salinity}

In the POP model, the increase in ML salinity during fall and winter in the western SCTR (Fig. 9a) is driven by meridional advection, while freshening in spring and early summer is driven by zonal advection. Freshening from surface fluxes peaks in January with the wet monsoon, maintaining the negative salinity tendencies at that time. During late winter when net evaporation is largest and would drive positive salinity tendencies, the surface flux is offset by the combination of the weaker but negative vertical processes, eddy and zonal-mean advection. In late spring, the reversal of the Indian monsoon winds over the Northern Hemisphere Indian Ocean weakens both the meridional advection of salt, reversing the southward currents that bring salty waters from the Arabian Sea, and the surface flux, with the onset of the rainy season in the TSIO. At the same time, freshening from zonal advection increases due to the inflow of low-salinity water from the east.

A similar picture emerges for the central domain (Fig. 9b): meridional advection dominates wintertime salinity increase and zonal advection dominates spring freshening. Here, however, the impact of advection is more pronounced, which explains why the amplitude of the salinity annual cycle is largest in the central TSIO. Throughout the year, surface freshwater fluxes are offset by vertical mixing such that tendencies are mostly driven by the imbalance between meridional and zonal advection. During spring, the salinity flux at the eastern boundary of the central domain is very large, driving the net zonal advection freshening, since in the western boundary the flux is negative but weaker (due to weaker westward currents), exporting fresher water to the west. As seen later, this mechanism is tied with MLT changes in the east.

The above results are consistent with the budget estimated from the gridded observations (Figs. 9d,e). Agreement between the POP model and the observations for tendencies and horizontal advection components, with few exceptions, is particularly encouraging. The residual curves imply a process that largely offsets the surface freshwater fluxes in similar fashion to the vertical processes in the model.

In the eastern end of the TSIO, MLS in the model exhibits a seasonal cycle that is nearly absent in the observations (e.g., Figs 9c,f and also Fig. 3b). Despite a strong seasonality in the $E-P$ pattern present in both model (Fig. 9c) and observations (Fig. 9f), it does not appear to drive the tendencies; the $E-P$ pattern in the east box, we note, is in sync with and of similar amplitude 


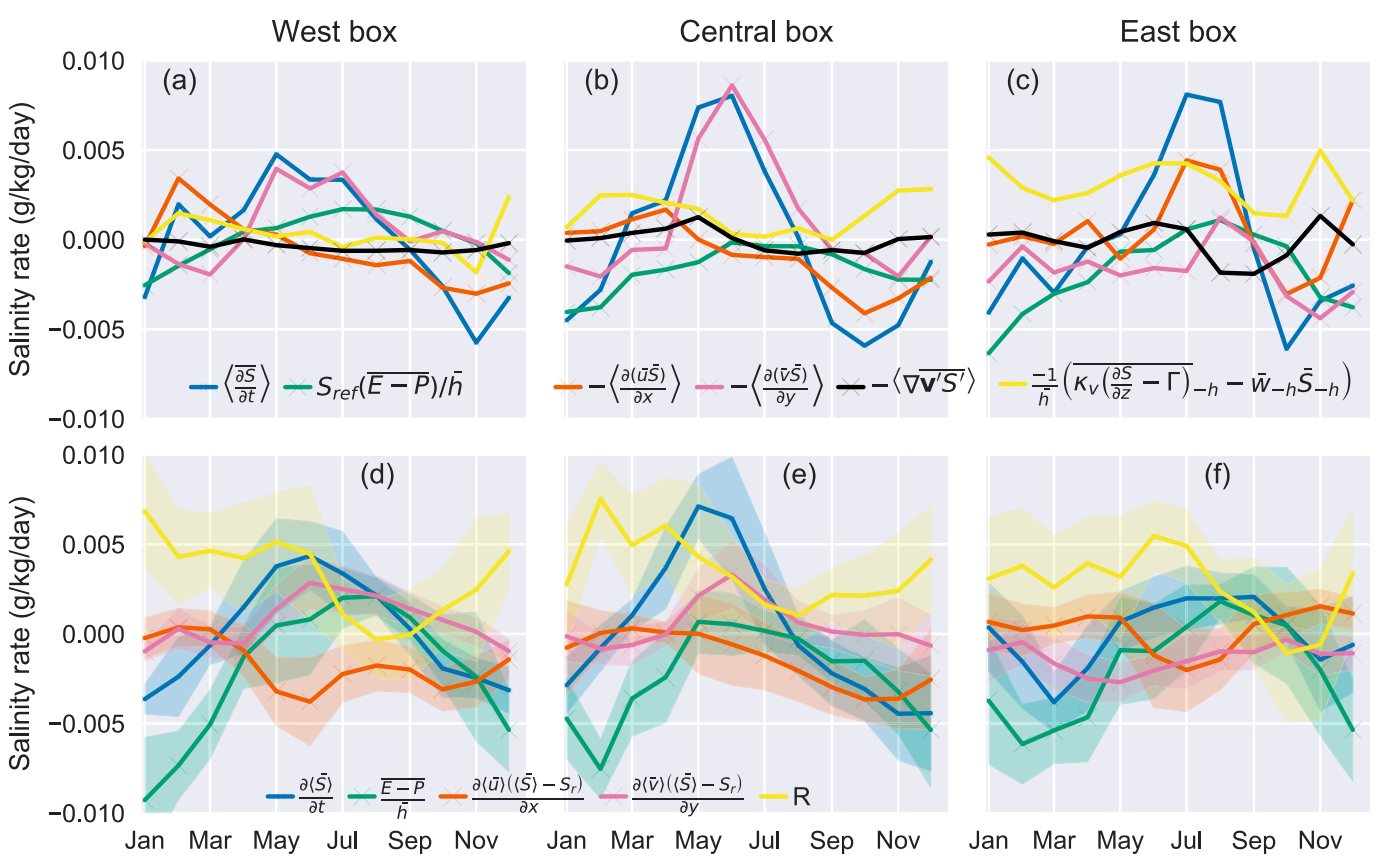

FIG. 9. Mixed layer salinity budgets for (top) POP and (bottom) observations (seasonal composites) volume averaged in the three domains shown in Fig. 1: (a),(d) west, (b),(e) central, and (c),(f) east. For the observationbased calculation, the background shading denotes the uncertainty in each term using the range of its monthly means from the 12 years of data. Labels are according to (1) and (3) for model and observations, respectively.

to the center of the basin, and model-observations agreement is good. The large model-observation disagreements for other terms and the large residuals in the observations make understanding MLS budgets challenging here. In the model budget, we see that the role of subsurface/vertical processes is much larger than to the west (arguably the leading term), supplying salt to the ML year round, thereby once again offsetting the surface flux-induced freshening during the wet season and making large contributions during the dry season. Consideration of both budgets together, however, suggests that no single mechanism drives the tendencies in any season.

There is less precipitation in the CORE forcing than in TRMM, and hence surface freshwater fluxes are weaker in the model than in the observations during the wet season. As a consequence, in the model west domain, only the January freshening tendency is driven by the surface fluxes, whereas in the observation-based budget the surface fluxes drive freshening tendencies from December through February. It is safe to say then that surface fluxes drive MLS tendencies during the peak wet season in the SCTR, but less so in the eastern TSIO.

Our results, from both model and observations, support a middle ground view between the conclusions of Halkides and Lee (2011) and Da-Allada et al. (2015), whereby ocean advection (in our case zonal) and surface fluxes control seasonal ML freshening in the SCTR, while meridional advection controls seasonal increases in MLS. In agreement with Halkides and Lee (2011), subsurface processes in the SCTR appear to be secondary for model MLS, but, as discussed in section 5d, may be more important in reality. These general assessments hold when we average the budget within the exact domain used by Halkides and Lee (2011) and DaAllada et al. (2015).

\section{b. Temperature}

The MLT budget for the model and observations is shown in Fig. 10. In contrast to MLS, the MLT seasonal changes in the TSIO are dominated by surface fluxes rather than horizontal advection. These results agree with first-order results of past studies, both in regards to the SCTR area (Foltz et al. 2010; Halkides and Lee 2011; Yokoi et al. 2012), as well as with those of Halkides and Lee (2009) for the eastern TSIO. All along the TSIO, temperature changes in both model and observations closely track the surface fluxes (although model and observed surface fluxes do not always agree), with a notable exception in late winter and early spring.

This does not imply that ocean dynamics are irrelevant. From late fall to spring (May-October), horizontal advection, specifically meridional advection driven by 

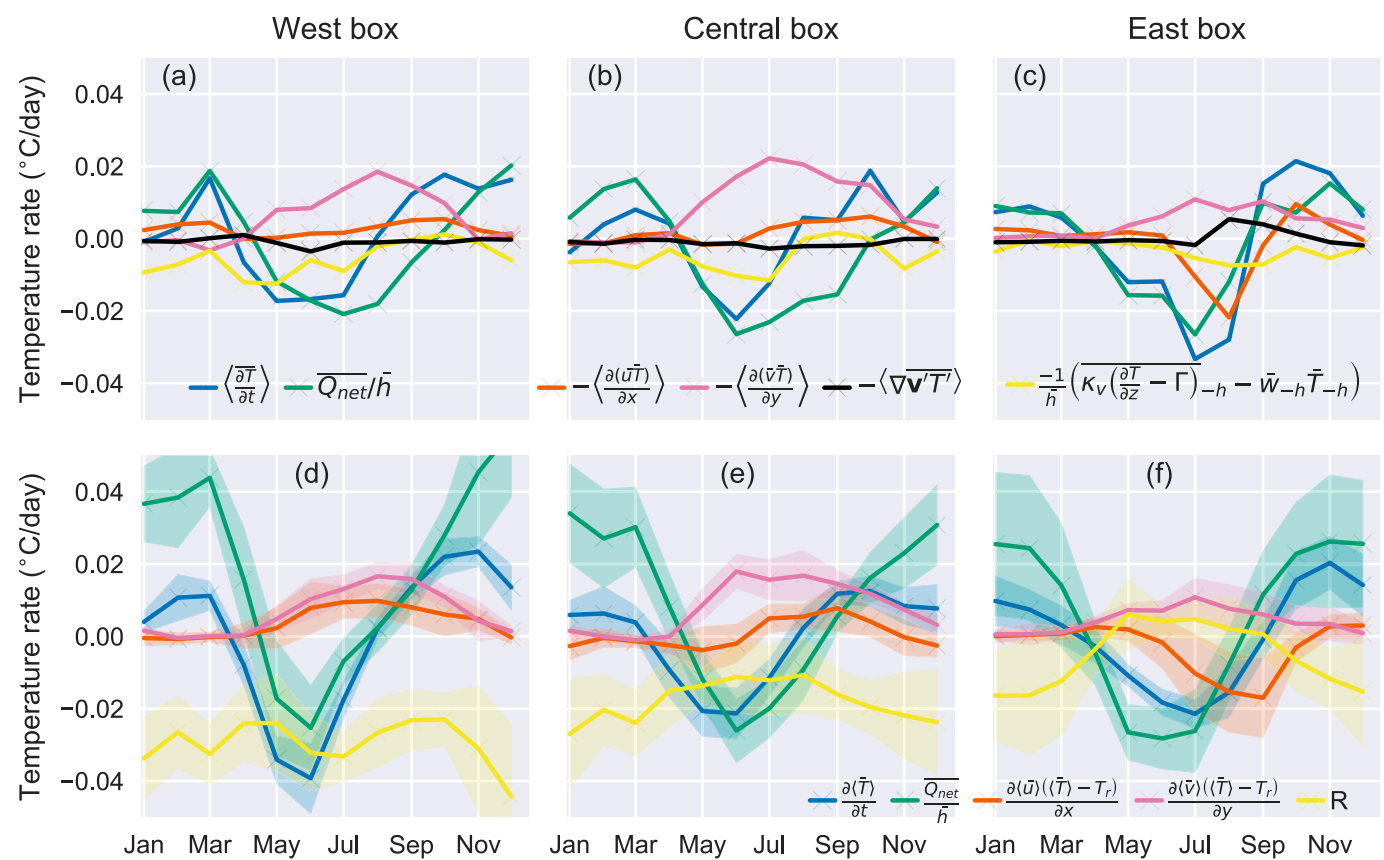

FIG. 10. As in Fig. 9, but for mixed layer temperature.

strong southward monsoon currents, supplies heat to the ML in the SCTR (Figs. 10a,b,d,e), countering some of the loss of heat from negative surface net heat fluxes and vertical/subsurface processes. In the east domain, although meridional advection (Figs. 10c,f) is also the primary supplier of heat offsetting late wintertime cooling by surface fluxes, it is weaker than to the west. From November to April, with the cessation of horizontal heat advection, warming is clearly driven by the surface fluxes in all domains.

From Fig. 3a, one can see that the MLT seasonal cycle is slightly out of phase across the TSIO: in the eastern end, it is coldest later (September vs August), and in the central area (roughly $75^{\circ}-95^{\circ} \mathrm{E}$ ), the cycle's amplitude is reduced, with little cooling during winter. Ocean dynamics also accounts for both features. Despite some (small) differences in the observed surface fluxes along the TSIO belt (e.g., shorter duration of cooling season in the west), they clearly cannot explain why the west domain sees much colder MLTs or why the east domain is coldest later.

The lag manifests in the warming tendencies occurring in late winter/early spring, in the west and central domains (Fig. 10), as well as with the cooling tendencies that remain through September in the east domain according to the observations (Fig. 10f). Recall that the warming (cooling) tendencies are more (less) prominent in the model because the entrainment/detrainment term is wrapped into the ML averaged tendencies [see (4) and Fig. 11]. The warming tendencies in the west and central domains are driven by a weakening and subsequent switch to a positive contribution from vertical processes, coupled to an increase in zonal advection of heat (Figs. 10a,b). This decrease in cooling by subsurface processes is caused by both a weakening of turbulent mixing and a large positive vertical advection spike (Figs. 11d,e). We attribute this reduction in subsurface influences to the combined effects of weakening winds and deepening thermocline, of which the latter can be associated with the annual Rossby wave. The increase in zonal advection warming is driven by large heat gains through the western boundary of the central and west domains.

Along the TSIO, MLTs start cooling around April (Figs. 10d-f), which, for the SCTR region, is before the surface net heat flux becomes negative (e.g., Figs. 10d,e). According to the model, the cause for the early cooling tendencies in SCTR are subsurface processes, particularly mixing and entrainment, as well as vertical advection in the west domain (Figs. 11d,e). The western SCTR sector experiences much colder winter MLTs when compared with the eastern SCTR because of stronger subsurface fluxes in fall that persist through to July, coupled with relatively less input of heat from the north all winter long (Figs. 10a,d vs Figs. 10b,e). The same argument helps explain the even larger differences in fall/winter MLT between the west and east domains (Fig. 3a).

We therefore deem that subsurface processes, even if overall secondary in magnitude to horizontal advection as the model suggests, make nonnegligible contributions 

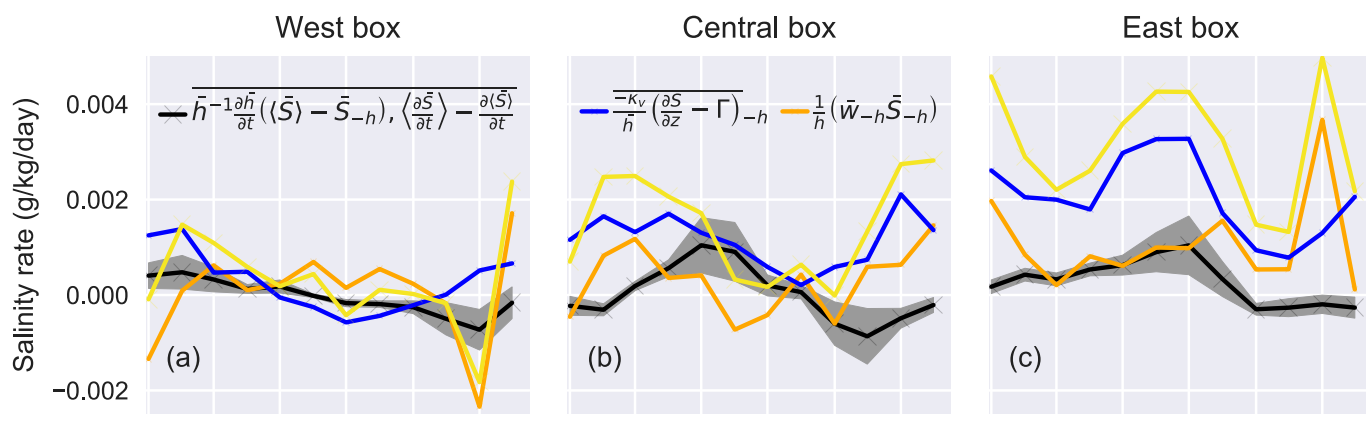

(c)
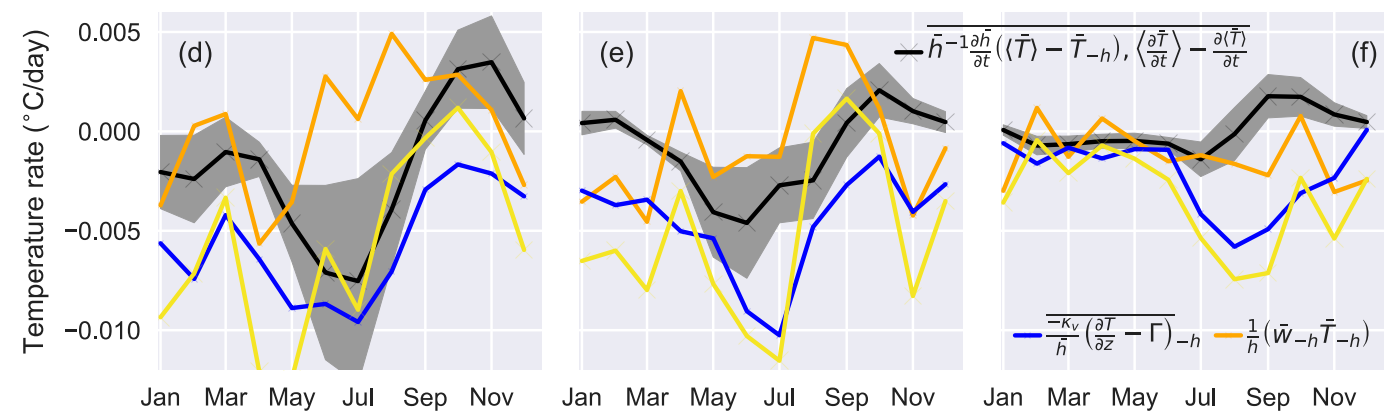

FIG. 11. Breakdown of vertical/subsurface terms in the POP (top) salt and (bottom) heat budgets in each domain. The yellow line is the same as in the top panels of Figs. 9 and 10, with individual contributions by mixing in blue and vertical advection in orange. The best estimate for the entrainment/detrainment term is shown in black, with the gray shading indicating its uncertainty (see section 4).

to the seasonal MLT evolution in the SCTR area. It is again a middle ground view between Halkides and Lee (2011) and Yokoi et al. (2012) about which is the dominant ocean mechanism.

The main characteristic of the eastern domain budget is the relative unimportance of vertical processes in the model heat budget for the majority of the year (Fig. 10c). Halkides and Lee (2009) obtained a similar result. Cooling by vertical processes is only significant in late winter and is largely counteracted by warming from eddy advection (yellows vs black lines in Fig. 10c). Given that strong southeast winds prevail during this time, the absence of subsurface influences in April-June indicates a strong influence of a depressed thermocline at this time (also associated with the Rossby wave). The resulting small cooling tendency during this period leads to the smaller amplitude of the MLT cycle east of $80^{\circ} \mathrm{E}$ (Fig. 3a).

Furthermore, unlike regions to the west, zonal advection in late winter and early spring promotes strong cooling of the ML (a robust result seen in both observations and model; Figs. 10c,f). This cooling is primarily due to westward currents that bring colder waters from farther east, from south of Java and the western Indonesian islands, and secondarily to the export of heat to the west in its western boundary (thus tied to the freshening of MLS in the central TSIO). This result is the opposite of what Halkides and Lee (2009) found. In the observations
(Fig. 10f), this negative zonal advection directly leads to a delay of MLT warming in the east, whereas in POP it leads to strong cooling in August (Fig. 10c). Zonal advection is, therefore, essential to explain the lag in the east TSIO MLT cycle.

\section{c. Vertical subsurface processes, annual Rossby wave, and eddy fluxes}

One of the key advantages of examining a model budget is the ability to accurately quantify the contribution of vertical or subsurface processes to the ML budget. Given their importance to the budgets, here we assess the relative role of vertical mixing by subgrid turbulence, vertical advection, and entrainment/detrainment.

As expected, of the subsurface components, vertical mixing is the most important source of cooling year round across the TSIO (all domains) and is particularly strong during winter, peaking in July (Figs. 11d-f), when winds are stronger. In the SCTR (Figs. 11d,e), cooling by vertical mixing has a seasonal minimum in October when the ML shoals and the thermocline deepens. In the east, vertical mixing of heat in the ML is generally weak from December to June, and strong from July to November. Vertical mixing of heat is weak in April-June, likely due to influence of the annual Rossby wave (Fig. 7). Of the subsurface processes, vertical mixing is also the main source of salt to the ML in the eastern 
domain year round (where it makes a large impact on the MLS budget) and an important one during November-May in the central domain; its contribution is small in the west domain, with loss of salt during winter [a result of large increases in sea surface salinity (SSS) from the model elevated evaporation rates].

Entrainment/detrainment generally follows the pattern of MLD change, which in turn generally follows the cycle of surface fluxes, leading to salinity increase and cooling in the ML when it deepens in fall/winter and freshening/warming when it shoals in spring. Although usually a smaller term than the combined mixing and advection, its contribution is nonnegligible during peak winter and spring (when detrainment occurs throughout the TSIO). Entrainment is particularly important for MLT in the west domain, presumably because of the much shallower thermocline therein, whereas its importance decreases to the east. For instance, in the west domain, during June/July, it may be about half of the averaged tendencies in the ML (Fig. 10a) and account for much of the difference between the types of tendencies shown in Figs. 10a and 10d. Entrainment of salt into the ML is comparatively much weaker (Fig. 11a), but as with all subsurface terms in the west domain, this is due to weak vertical salinity gradients in this region (at least in POP). Entrainment and detrainment of salt is, as the other subsurface components are, more important in the central and east domains, where strong vertical salinity gradients can develop due to the presence of nearsurface fresher lenses (e.g., Fig. 2c).

Vertical advection is much more variable, and contributes both positively and negatively, often opposing vertical mixing for both MLT and MLS budgets; in general its impact on the budgets, in all domains, is smaller than mixing, with the exception of a few periods (e.g., September in Fig. 11e). We are unsure if any single process drives vertical advection in these areas; it is likely that this term is controlled by a complex combination of ML dynamics and thermocline adjustments (i.e., Rossby waves).

The annual Rossby wave is slow enough (Fig. 7) that it should imprint itself into the monthly means we work with. Attribution to MLT/MLS seasonal anomalies, however, is challenging, as there is no signature of the wave in the horizontal convergences of heat/salt, and subsurface fluxes are often also associated with winds and boundary layer dynamics. The impact seems to manifest clearly only in reductions of subsurface cooling during certain periods. In contrast, reductions in positive salt fluxes from vertical processes do not correlate well with thermocline deepening; the aforementioned surface lenses common in the freshening seasons are the likely modulators of these fluxes. (We explore this in detail in a subsequent study.) Hence we think that the overall Rossby wave influence on seasonal MLT/MLS is small, and limited in space and time, which is generally hinted at in Fig. 7. This does not rule out indirect influence by the wave in the westward migration of patterns (see section 6a).

One of our goals is to assess the role of eddies in the ML heat and salt budgets, which was previously overlooked (e.g., Halkides and Lee 2011; Da-Allada et al. 2015). For the most part, we find that the contribution of eddy variability to the MLT and MLS seasonal budgets is small (see black lines in Figs. 9 and 10). In the MLT (MLS) budget, eddy variability mostly contributes with cooling (freshening) year-round in the west and central domains, with a few notable reversals in late summer/ early fall (e.g., Fig. 9b). In the eastern domain, eddy variability makes a significant (in relation to other terms) impact on MLS, but similarly to other domains a weak impact on MLT, with the exception of August when it induces significant warming.

Although POP captures the spatial pattern and the seasonality of EKE in the TSIO, it underestimates the magnitude of EKE, roughly by a factor of 2 (see Fig. 8a). This is still insufficient to make eddy fluxes a significant term (in relation to other dominant processes), except perhaps for July-September in the eastern TSIO. We discuss the role of eddy variability under a different context in section 6b, when we look at the CINDY2011 data and particle trajectories.

\section{d. Model budgets versus observation budgets: Understanding the residuals}

Residuals in calculated heat and salt budgets are often attributed to unresolved processes. Here, by comparing the full model budgets with their observationderived counterparts, we are able to assess where the two methods agree, and consider the consistency of residuals in the latter with specific processes, and where there is disagreement. It is important to highlight again the general good agreement between model and observations for all comparable terms (i.e., tendencies and horizontal advection), lending confidence to both the model results and our estimates derived from the measured data. To make these comparisons we must rescale the POP surface and vertical fluxes to try to account for the bias in MLD (a doubling factor depending on the time of the year and region). The bias in MLD affects little the other terms.

Using the model balance as a guide, the positive residuals in the west MLS budget (Fig. 9d) are not likely resulting from vertical fluxes or entrainment, which are too small during most of the year (Figs. 9a and 11a). Attribution to any missing process is particularly difficult here because of differences in the role of zonal 
advection between model and observational budgets (red lines in Figs. 9a and 9d). For the west domain MLT budget (Fig. 10d), missing vertical mixing and entrainment likely account for most of the residuals in JanuaryJuly (see Figs. 10a and 11d).

In the central domain, the MLS residuals (Fig. 9e) during summer are consistent with the model's vertical flux pattern (and in sometimes also with the eddy fluxes) (Fig. 9b), and these explain most of the residuals during most of the year. The MLT residuals in the central domain (Fig. 10e) are mostly accounted for by the combination of vertical fluxes and entrainment (Figs. 10b and 11e), with the exception of a few months. The smaller residuals in the central domain are also consistent with the model-predicted reduction in entrainment cooling, relative to the west. In the west and central domains, the residuals during August-December, when vertical fluxes are weaker and ML shoaling leads to detrainment in the model, remain mostly unaccounted for.

Because of large model-observations disagreement in the east for resolved budget terms, the model is not as useful to diagnose the MLS budget. The residuals (Fig. 9f), however, are fully consistent with the strong positive salt fluxes into the ML from vertical processes seen in the model (Fig. 9c). For MLT, the model indicates that vertical processes (Fig. 10f) do not contribute significantly to the negative residuals in summer, and so we cannot explain these. The small positive residuals during June-September (Fig. 10f) may be related to small biases in the advection components, since the meridional heat gain is larger in the model than the observations (pink lines in Figs. 10c and 10f), which show weaker southward currents (e.g., Fig. 4).

As discussed above, not all the residuals can be ascribed to missing processes provided by the model. Sometimes, residual attribution to subsurface processes is blurred by model-observation quantitative disagreement on advection terms (e.g., meridional advection of salt is higher in the model during fall and winter in the central domain). Lateral induction in the model advective term is not likely to account for such disagreements, as this term is usually estimated to be no more than $10 \%-20 \%$ of mean ML advection (e.g., Kim et al. 2007); model-observation differences in circulation and tracer distribution likely drive the disagreements in horizontal advection; furthermore we remind the reader that advection in the observations is inherently subject to large sampling uncertainty and cannot be easily checked for biases. Tendencies, on the other hand, after factoring the entrainment/detrainment, are in excellent agreement in all regions.

Even after MLD rescaling, model surface freshwater (heat) fluxes during the warm and wet summertime are weaker (only slightly weaker) than in the observations. We find no significant biases in the observed surface fluxes (see appendix A for a description of random error and bias estimation), such that residuals during these times may indicate that exchanges with the subsurface are more vigorous than implied by the model (rather than errors).

\section{Impact of seasonal cycle on upper ocean variability in the SCTR}

\section{a. Seasonal westward jet}

In late winter and spring, the onset of southeast trade winds and the associated Ekman pumping over the eastern half of the basin trigger mass adjustments that are communicated to the SCTR, on the time scale of several months, via the annual Rossby wave (Périgaud and Delecluse 1992; Masumoto and Meyers 1998; Schott et al. 2009; Trenary and Han 2012). A thermocline depression then spreads westward from the southeast trailed by westward currents between approximately $12^{\circ}$ and $8^{\circ} \mathrm{S}$ (Fig. 12; see also Fig. 7d).

This seasonal near-surface jet in the wake of the annual Rossby wave (e.g., Figs. 12d-f), appears to have not been described before, but likely is comprised of a geostrophic component [as detected over many depths by Johnson (2011)] caused by thermocline displacements and an Ekman, wind-forced component. First appearing around June (Fig. 12a) as part of the South Java Current, it subsequently strengthens and expands westward until it connects with the SEC, reaching the edges of the SCTR by November-December (Fig. 12f). The jet currents disappear in the east during the northwest monsoon (Fig. 12b). Despite the obvious association (e.g., Fig. 7d), it is unclear at this point how much the annual Rossby wave controls the jet's space-time variability, as well as its relationship to the Java-South Equatorial Current system, versus direct wind forcing.

As shown in section 5, the jet impacts the seasonal MLT (east lag) and MLS budgets (central freshening ahead of wet season) through the zonal advection term. The jet is also present in 2011 [see Figs. 5 and 6 of Seiki et al. (2013)], but it was not identified as such by the authors, even though they recognize that waters observed during November 2011 come from the southeastern TSIO. We now demonstrate that this jet transports distinct eastern waters and affects upper ocean structure in the western TSIO/ SCTR as observed during CINDY2011.

\section{b. Water mass origins: Results of particle tracking}

Observations at $8^{\circ} \mathrm{S}, 80.5^{\circ} \mathrm{E}$ in mid-November 2011 show the arrival of a colder and fresher water mass (Figs. 2c,d) in the upper $100 \mathrm{~m}$, after the thermocline deepening in 
(a) Jun $z 20^{\circ} \mathrm{C}$ and total currents

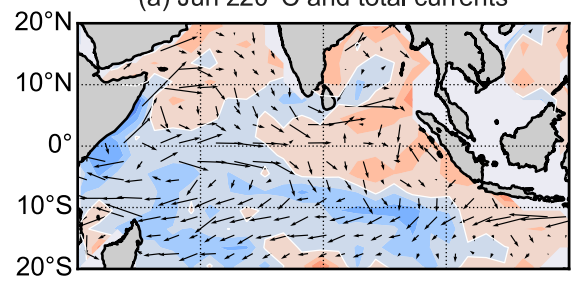

(c) Aug $z 20^{\circ} \mathrm{C}$ and total currents

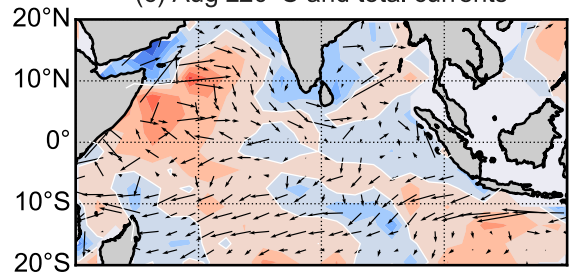

(e) Oct $z 20^{\circ} \mathrm{C}$ and total currents

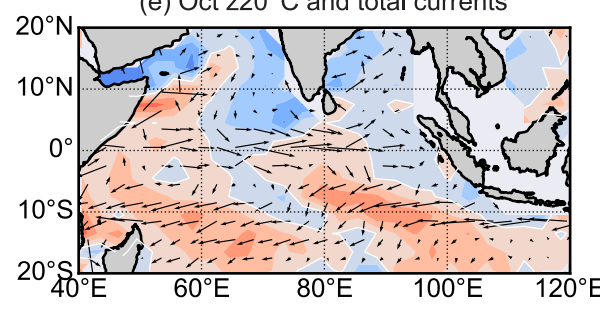

(b) Jul $z 20^{\circ} \mathrm{C}$ and total currents

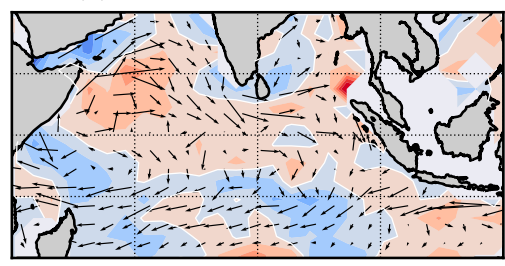

(d) Sep $z 20^{\circ} \mathrm{C}$ anom and total currents

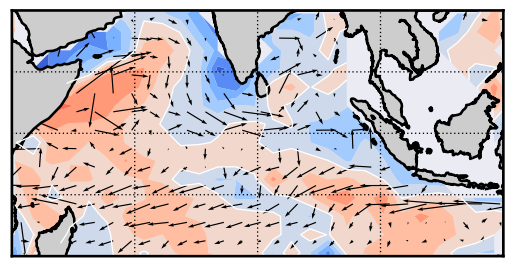

(f) Nov $z 20^{\circ} \mathrm{C}$ anom and total currents

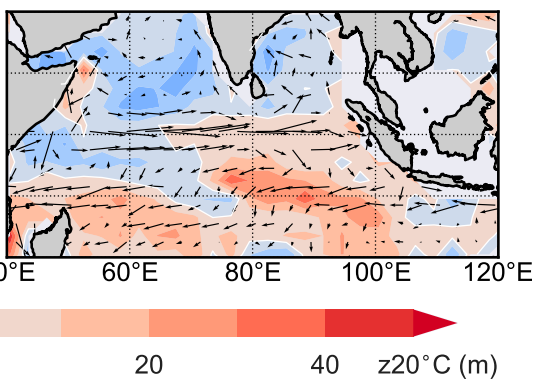

$0.25 \mathrm{~m} / \mathrm{s}$

$$
-20
$$

0

FIG. 12. Maps of Argo-derived, climatological seasonal anomalies of the depth of $20^{\circ} \mathrm{C}$ isotherm $\left(\mathrm{z} 20^{\circ} \mathrm{C}\right)$ for select months overlain with vectors of monthly averaged near-surface currents from OSCAR.

October, associated with a decrease in SST and surface salinity (Fig. 2b). An examination of the meteorological observations from the ship (Fig. 2a) and RAMA buoy network is sufficient to see that local freshwater fluxes are too small to cause the anomalous freshening, and that heat fluxes are net warming. We attribute this cooling to indirect impacts of the seasonal advection of east TSIO waters by the westward jet in the wake of the Rossby wave, namely, to variations in the transport of east TSIO waters by eddies embedded in the jet.

To illustrate this point, in Fig. 13 we plot the trajectories and associated temperature and salinity history of virtual water parcels backtracked through MERCATOR's surface flow field, starting 11 November around $8^{\circ} \mathrm{S}, 80.5^{\circ} \mathrm{E}$. The trajectories confirm the far eastern TSIO origins of water particles. The trajectories complement our analysis of ML salt and heat fluxes in the central and east domains of section 5, since, according to the Argo record (Figs. 14a,b), 2011 is a typical year, with weak ML anomalies as well as near-normal circulation, and hence representative of the seasonal mechanism we describe.

We draw attention now to the fresher and often slightly colder lenses in the ML seen October-early November in the CINDY2011 observations (Figs. 2b-d), prior to the arrival of the east water mass in the second week of November. The lenses cannot be explained by local surface fluxes either (see the lack of rainfall in Fig. 2a); they were not discussed by Seiki et al. (2013), who focus solely on SST changes. Seiki et al.'s heat budget [see Fig. 11 in Seiki et al. (2013)] indicates surprisingly small roles for advection during these times. We note, however, that there is a large residual in their budget, suggesting possible large errors in some of the terms, and their interpretation of the heat budget for the abrupt cooling is inconsistent with their particle tracking and direct eastern origin of water parcels.

The MERCATOR $T / S$ history of the tracked parcels helps in understanding the role of eddy transport, which we define here as any flow with variability with time scale shorter than a month. In 2011, water parcels originate off the coast of Sumatra and Java, with three main water types being obvious (warmer in the north, colder in the south, very fresh from near the Sunda Strait). Parcels are then transported nearly zonally between approximately $105^{\circ}$ and $80^{\circ} \mathrm{E}$, consistent with the seasonal jet pattern, although trajectories in the southern 
branch are subject to substantial influence by eddies that are more active in this area during July-December (e.g., Feng and Wijffels 2002). Using monthly averaged OSCAR or POP currents when computing trajectories also corroborates the general eastern origins of the water parcels, but the trajectories show a more directly eastern origin in OSCAR and a more northeastern origin in POP, without branching.

When the history of the water parcels is examined, we note that waters from the northern branch cool and then warm, whereas the waters from the southern branch tend to steadily warm as they are transported westward (although with some intraseasonal variations), and waters from all branches become progressively saltier (also with some intraseasonal variations in the southern branch). The water types mix both laterally and vertically along the track, retaining their relative low salinity and cool temperatures, with the source of the particles equally split $(\approx 1 / 3)$ between the south, north, and Sunda Strait branches.

These changes suggest, not surprisingly, that the eastern water mass $T / S$ signature in the ML can be substantially eroded. The average of end point $T / S$ matches well with the $T / S$ of the $70-\mathrm{m}$ water type in CINDY2011 ( $\sim 27^{\circ} \mathrm{C}, 34$ psu; Figs. 2c,d), lending further confidence to our origin interpretation. The complex along-track $T / S$ history, subject to substantial mixing and to the influence of atmospheric fluxes, adds to the character of the intraseasonal SST and SSS variations observed in CINDY2011 and supports the notion that the ML lenses are products of eddy transport. To properly understand the contribution of remote processes (e.g., upstream precipitation and lateral stirring) to the evolution of intraseasonal SST anomalies, however, will require one to budget the history of water parcels along their trajectory. These fresher and colder near-surface lenses, as well the water mass centered around $70 \mathrm{~m}$, also impact the stratification in the upper ocean and may impact ML dynamics, something we explore in a future investigation. For our purposes here, the particle trajectory history and $T / S$ signature support the assertion that the seasonal jet underscores most of the observed changes in SST and SSS at $8^{\circ} \mathrm{S}$, $80.5^{\circ} \mathrm{E}$.

\section{Conclusions and discussion}

The seasonal cycles of mixed layer (ML) temperature and salinity along the TSIO are the subject of this investigation. To understand the processes driving the seasonal cycle in this vast region, we calculated ML salt and heat budgets in a model and in gridded observations for three subdomains, covering the western and eastern
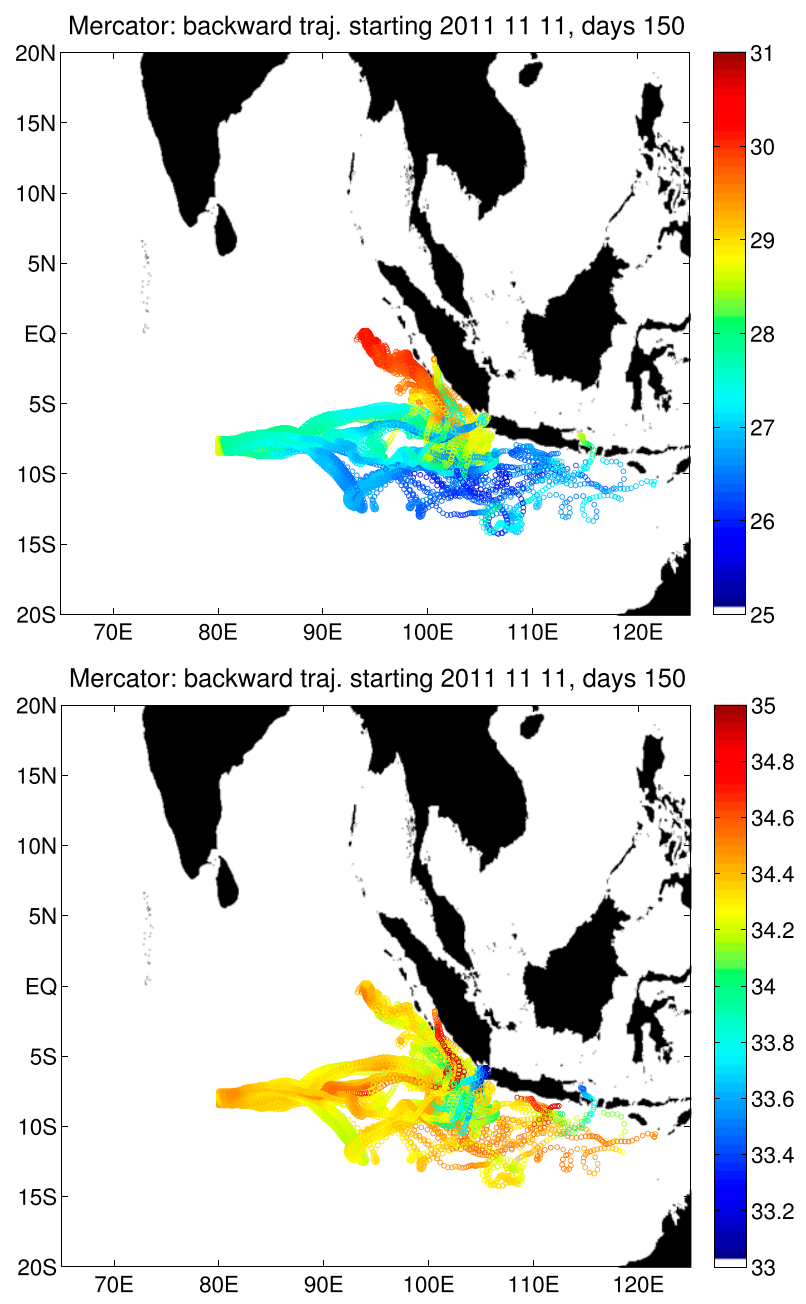

FIG. 13. Near-surface (upper 20-m average) virtual parcel trajectories back-tracked for 150 days starting 11 Nov 2011 around $8^{\circ} \mathrm{S}, 80.5^{\circ} \mathrm{E}$. Circles mark the daily float position with colors showing the (top) temperature and (bottom) salinity of the model water parcels.

sectors of the Seychelles-Chagos thermocline ridge (SCTR; west and central boxes) and the easternmost area, off the coast of Java and Sumatra (east box). Our main conclusions are as follows:

- Ocean dynamics control seasonal changes of mixed layer salinity (MLS; Fig. 9) in the SCTR (west and central domains); meridional advection drives increases in ML salinity in austral fall-winter whereas zonal advection drives ML freshening in spring-summer. Surface freshwater fluxes play a secondary role, driving ML freshening in the peak wet season (DJF). In the eastern TSIO, the budgets were inconclusive, with no dominant process, perhaps reflecting the weak seasonality observed in this region.

- Surface fluxes control the seasonal cycle of mixed layer temperature (MLT; Fig. 10) in all three domains, in 

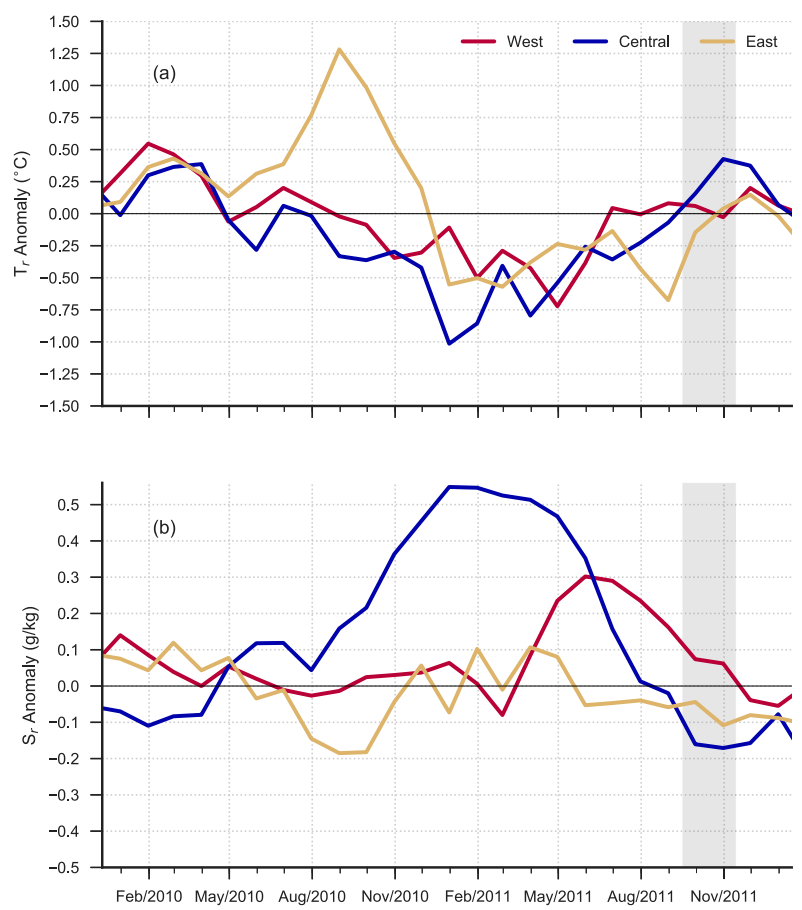

FIG. 14. Time series of domain volume averaged anomalies of mixed layer (a) temperature and (b) salinity derived from the Argo product. Anomalies obtained by removing the seasonal cycles shown in Fig. 3 from the full record. The domains used for averaging are shown in Fig. 1. The light gray shading indicates the period of the CINDY2011 measurements.

agreement with previous studies (e.g., Foltz et al. 2010; Halkides and Lee 2011). However, during late winter and early spring we show that zonal advection leads to early warming in the west (when combined with subsurface processes) and early cooling in the east, explaining a 1-month lag/lead in the cycle between east/ west (e.g., Fig. 7). Ocean processes are also important to explain the slower cooling of and general warmer MLT in the east TSIO during fall.

- In POP, vertical/subsurface processes (Fig. 11) play a secondary, albeit nonnegligible, role in meridional (zonal) advection for seasonal MLT (MLS) changes in the SCTR. In the eastern TSIO, they are important for MLS, mainly because of stronger salinity stratification near the surface in this region, but less so for MLT because of the deep thermocline associated with the annual Rossby wave when the strong southeast trades are blowing. In all three domains, turbulent mixing dominates cooling and an increase in salinity year round, while entrainment and vertical advection are secondary and often oppose mixing. As a consequence, vertical processes do not display a clear seasonal cycle, unlike suggested in Foltz et al. (2010).
- There is qualitative and, in several instances, quantitative agreement between the model- and observation-based budgets. But we note that model surface heat and freshwater fluxes are weaker than in the observations (in great part due to the model biased-deep ML), and furthermore, that observation residuals are often large, indicating that vertical processes may be more important in reality than the model suggests. We stress the importance of taking into account the uncertainty, including possible biases, in the observation-based estimates of budget terms when interpreting its residuals.

- The model budgets indicate that, in general, eddy fluxes contribute little to the seasonal MLT and MLS changes across the TSIO, with the exception of certain months in the east region. This assertion likely holds true despite the fact that POP somewhat underestimates the surface EKE. Previous studies, due to their coarse resolution or limited spatial coverage, have not been able to evaluate the impact of eddy activity on seasonal ML budgets.

The conclusions above are qualitatively robust for the chosen areas, which were chosen to highlight the differences and similarities in the dynamics across the TSIO. Quantitatively, however, there is substantial sensitivity in the budgets to the meridional limits for the west and central domains. This sensitivity occurs because the annual cycle north of $6^{\circ} \mathrm{S}$ is out of phase with the cycle to the south and is influenced by a semiannual cycle; in contrast, extensions to $15^{\circ} \mathrm{S}$ impact little our results. Nonetheless, we deem our results applicable to the whole TSIO.

Past research has taken a fragmented look at the seasonal budgets, choosing to focus on one specific area only. We highlight the role zonal advection plays in connecting the changes in the east with those in the west. The influence of Rossby waves and associated changes in thermocline depth on MLT and MLS is limited to certain months and even then is of secondary importance. Thus, we are able to explain certain features of the MLT and MLS cycles that have been previously overlooked, such as the lag in the MLT cycle in the eastern TSIO and the early observations by Menezes et al. (2014), which show a poor relationship of SSH and SSS in the Indian Ocean between 2011 and 2013.

In taking a comprehensive view, we are also able to identify the timing when the seasonal cycle and its driving mechanisms are more susceptible to perturbations that can impact the TSIO climate. Currents from the observations and models used here show a seasonal westward jet centered at $8^{\circ} \mathrm{S}$ that occurs in 
the wake of the annual downwelling Rossby wave, as part of the adjustments to the onset of dry monsoon winds in the eastern side of the basin. This jet essentially controls the zonal advective term, and thus drives the widespread ML freshening in the SCTR region and the cooling in the east during late winter and spring, in agreement with early work by Durand et al. (2013). Particle tracking results corroborate that, in a typical year, such as 2011, the jet brings relatively fresher/colder waters from the east to the central TSIO, materially connecting the two regions. Although this influence wanes to the west, into the core of the SCTR, where meridional and vertical processes are also important, we posit spring to be a pivotal time throughout the TSIO. At this time, TSIO climate patterns would be sensitive to perturbations of this east-to-west water transport, which could originate from variability in the monsoon winds or in source waters. Further research into the underlying dynamics of the jet, therefore, may prove useful to understand its variability. The implications of this seasonal water exchange to scale interactions at the high-frequency (intraseasonal SST fluctuations) and low-frequency (IOD events) ends of the spectrum of air-sea interaction variability are addressed in follow up studies.

Acknowledgments. Funding was provided by $\mathrm{Na}-$ tional Oceanic and Atmospheric Administration (NOAA) Grant NA13OAR4310168. FOB was supported by the National Science Foundation through its sponsorship of NCAR. Argo data used here were collected and made freely available by the International Argo Program and the national programs that contribute to it. (http://www.argo.ucsd.edu, http://argo. jcommops.org). The Argo Program is part of the Global Ocean Observing System. We would like to acknowledge high-performance computing support from Yellowstone (ark:/85065/d7wd3xhc) provided by NCAR's Computational and Information Systems Laboratory, sponsored by the National Science Foundation. All gridded data products used here were provided by the Asia-Pacific Data Research Center, which is a part of the International Pacific Research Center at the University of Hawai'i at Mānoa, funded in part by the NOAA. Access to MERCATOR OCEAN global analysis graciously provided by Mercator Océan of France (http://www.mercator-ocean.fr). We thank the R/V Mirai captain and crew, as well as Andrei Natarov, for collecting the CINDY2011 shipboard data. RAMA buoy data were provided by the GTMBA Project Office of NOAA/PMEL. We also thank F. Ascani for kindly providing the particle trajectory software, J. Vialard for discussions of heat and salt budgets along the thermocline ridge, and the three anonymous reviewers for comments that greatly improved the manuscript.

\section{APPENDIX A}

\section{Budget Uncertainty and Bias Estimation}

Uncertainty in the tracer ( $T$ or $S$ ) tendency and advective terms of (3) is quantified by propagating sampling errors in the monthly ML tracer fields $\bar{T}$ and $\bar{S}\left(\varepsilon_{\bar{T}}\right.$ and $\varepsilon_{\bar{S}}$, respectively), and in monthly averaged OSCAR $u$ and $v$ currents ( $\varepsilon_{\bar{U}}$ and $\varepsilon_{\bar{V}}$, respectively) as

$$
\begin{gathered}
\varepsilon \frac{\partial \bar{T}}{\partial t}=\frac{\left(\sqrt{\varepsilon_{\bar{T}_{t+1}}^{2}+\varepsilon_{\bar{T}_{t-1}}^{2}}\right)}{2 \Delta t}, \\
\varepsilon \frac{\partial \bar{u} \bar{T}}{\partial x}=\frac{\left(\sqrt{\varepsilon_{(\bar{U} \bar{T})_{x}}^{2}+\varepsilon_{(\bar{U} \bar{T})_{x+1}}^{2}}\right)}{\Delta x}, \\
\varepsilon \frac{\partial \bar{v} \bar{T}}{\partial y}=\frac{\left(\sqrt{\varepsilon_{(\bar{V} \bar{T})_{y}}^{2}+\varepsilon_{(\bar{V} \bar{T})_{y+1}}^{2}}\right)}{\Delta y},
\end{gathered}
$$

where $\Delta t=1$ month, $\Delta x=\Delta y=1^{\circ}$ and $\varepsilon_{(\bar{U} \bar{T})_{x}}=$ $\sqrt{\varepsilon_{\bar{U}}^{2} \bar{T}^{2}+\varepsilon_{\bar{T}}^{2} \bar{U}^{2}}, \varepsilon_{(\bar{V} \bar{T})_{y}}=\sqrt{\varepsilon_{\bar{V}}^{2} \bar{T}^{2}+\varepsilon_{\bar{T}}^{2} \bar{V}^{2}}$ are the errors of the zonal and meridional tracer flux, respectively.

To estimate $\varepsilon_{\bar{T}}$ and $\varepsilon_{\bar{S}}$ as a function of time and domain, we use an area-averaged (equal to our boxes) of the tracer's one standard deviation from the $3^{\circ} \times 3^{\circ}$ binned Argo ML product. This is needed because the $1^{\circ} \times 1^{\circ}$ objectively interpolated product does not output errors. Based on reported root-mean-square differences (RMSDs) between OSCAR and drifter velocities for the TSIO (http://oscarweb.esr.org/drifters. php), we use constant values of 0.10 and $0.09 \mathrm{~m} \mathrm{~s}^{-1}$ for $\varepsilon_{\bar{U}}$ and $\varepsilon_{\bar{V}}$, respectively, after taking into account our monthly averaging of the OSCAR data.

The surface freshwater fluxes uncertainty is estimated as

$$
\varepsilon_{\mathrm{SFF}}=\sqrt{\frac{\bar{S}^{2}}{\bar{h}^{2}}\left[\varepsilon_{\bar{E}}^{2}+\varepsilon_{\bar{P}}^{2}+\frac{(\bar{E}-\bar{P})^{2}}{\bar{h}} \varepsilon_{\bar{h}}^{2}\right]+\left(\frac{\bar{E}-\bar{P}}{\bar{h}}\right)^{2} \varepsilon_{\bar{S}}^{2}}
$$

where $\varepsilon_{E}$ is the evaporation error reported in OAFlux, $\varepsilon_{P}$ is the error in precipitation reported in TRMM, and $\varepsilon_{\bar{h}}$ is the uncertainty in the MLD estimated as done for $\bar{T}$ and $\bar{S}$. Likewise, for surface heat fluxes we use 


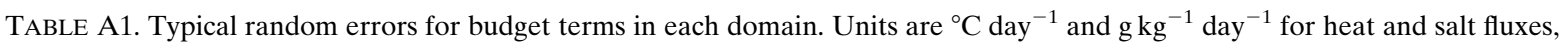
respectively. Value in parentheses for surface heat flux error is the estimate using ISCCP instead of ERA-I.

\begin{tabular}{lrrr}
\hline \hline Variable & West & Central & East \\
\hline$\varepsilon \frac{\partial \bar{T}}{\partial t}, \varepsilon \frac{\partial \bar{S}}{\partial t}$ & $4.8 \times 10^{-3}, 1.7 \times 10^{-3}$ & $2.8 \times 10^{-3}, 1.2 \times 10^{-3}$ & $4.6 \times 10^{-3}, 2.6 \times 10^{-3}$ \\
$\varepsilon \frac{\partial \bar{U} \bar{T}}{\partial x}, \varepsilon \frac{\partial \bar{U} \bar{S}}{\partial x}$ & $7 \times 10^{-3}, 2.2 \times 10^{-3}$ & $7 \times 10^{-3}, 2 \times 10^{-3}$ & $1 \times 10^{-2}, 3.6 \times 10^{-3}$ \\
$\varepsilon \frac{\partial \bar{V} \bar{T}}{\partial y}, \varepsilon \frac{\partial \bar{V} \bar{S}}{\partial y}$ & & & \\
$\varepsilon_{\mathrm{SHF}}, \varepsilon_{\mathrm{SFF}}$ & $5.4 \times 10^{-3}, 1.6 \times 10^{-3}$ & $5.7 \times 10^{-3}, 1.5 \times 10^{-3}$ & $7.7 \times 10^{-3}, 2.4 \times 10^{-3}$ \\
& $3(2.2) \times 10^{-3}, 2.5 \times 10^{-4}$ & $2.7(2) \times 10^{-3}, 2.3 \times 10^{-4}$ & $3.8(2.9) \times 10^{-3}, 3.6 \times 10^{-4}$ \\
\hline
\end{tabular}

$$
\varepsilon_{\mathrm{SHF}}=\sqrt{\frac{1}{\bar{h}^{2}}\left(\varepsilon_{\bar{Q}}^{2}+\varepsilon_{\bar{q}_{-h}}^{2}\right)+\frac{1}{\bar{h}^{4}}\left(\bar{Q}-\bar{q}_{-h}\right)^{2} \varepsilon_{\bar{h}}^{2}}
$$

with $\varepsilon_{\bar{Q}}=\sqrt{\varepsilon_{\mathrm{LH}}^{2}+\varepsilon_{\mathrm{SH}}^{2}+\varepsilon_{\mathrm{SW}}^{2}+\varepsilon_{\mathrm{LW}}^{2}}$ and $\varepsilon_{\bar{q}_{-h}}=$ $\sqrt{\varepsilon_{\mathrm{SW}}^{2} A^{2}+\varepsilon_{\bar{h}}^{2} \bar{Q}_{\mathrm{SW}}^{2} B^{2}}$, where

$$
\begin{aligned}
& A=0.62 \exp \left(\frac{-\bar{h}}{0.60}\right)+0.38 \exp \left(\frac{-\bar{h}}{20.0}\right) \text { and } \\
& B=1.03 \exp \left(\frac{-\bar{h}}{0.60}\right)+0.019 \exp \left(\frac{-\bar{h}}{20.0}\right)
\end{aligned}
$$

are the parameters for the Jerlov water type $1 \mathrm{~A}$. In the above, $\varepsilon_{\mathrm{LH}}$ and $\varepsilon_{\mathrm{SH}}$ are, respectively, the objective interpolation errors for the latent and sensible heat fluxes reported in OAFlux; $\varepsilon_{\mathrm{SW}}$ and $\varepsilon_{\mathrm{LW}}$ are, respectively, the shortwave and longwave radiation fluxes errors in ISCPP and ERA-I data. The latter two are estimated as the product's RMSD to monthly means formed from available flux data in RAMA buoys within the TSIO. Because of the buoy's limited spatial and temporal coverage, these errors are taken to apply in all three domains.

All errors above are assumed to be random and uncorrelated. Equations (A1)-(A5) are estimated at each grid point $i$ and then domain averaged as

$$
\bar{\varepsilon}=\frac{1}{N} \sqrt{\sum_{i=1}^{N} \varepsilon_{i}^{2}},
$$

where $N$ is the total number of points within the domain. Table A1 gives typical errors estimated for the budget terms in each domain. The sampling errors can be quite high, particularly for advection, but the magnitude of these errors decreases by a factor of $1 / \sqrt{12}$ in the climatological means we examine here. These sampling errors are relevant when examining a particular year.

Using the RAMA buoy data, we also examine biases in the fluxes from gridded products. Any biases are likely to impact our budgets the most during summer when the ML is shallowest. For the net freshwater fluxes, the OAFlux/TRMM combination show a very small
( $1 \%-5 \%$ of typical fluxes) wet bias, largely due to differences in precipitation between TRMM and the rain gauges. For the latent heat flux component, the bias is at most $4 \mathrm{~W} \mathrm{~m}^{-2}$ warmer; for the sensible component, the bias is less than $0.5 \mathrm{~W} \mathrm{~m}^{-2}$. Shortwave radiation fluxes on the other hand, have a $10-12 \mathrm{~W} \mathrm{~m}^{-2}$ warm bias. Only two buoys have (one buoy has) usable data, providing no more than 47 (12) overlapping months to compare longwave radiation measurements to ERA-I (ISCCP). The bias in the gridded longwave radiation is calculated at $15-20 \mathrm{~W} \mathrm{~m}^{-2}$ more cooling; the combined net heat flux at the surface is estimated to be $-5 \mathrm{~W} \mathrm{~m}^{-2}$ (using ERA-I; near zero using ISCCP/OAFlux), but this number must be viewed with caution due to the limited data for comparison. The biases reported for ERA-I here are calculated after a bias correction is applied. This correction is done at every grid point by adding the bias from a linear regression between ERA-I and ISCCP radiative fluxes using data for the overlapping period (2005-09) of the two products, wherever the regression coefficient passes a goodnessof-fit test at $95 \%$ significance level.

\section{APPENDIX B}

\section{Particle Tracking}

To backtrack the virtual water parcels through a model flow field $\mathbf{u}$ as passive particles, we solve

$$
\frac{d \mathbf{x}}{d t}=\mathbf{u}
$$

numerically with a fourth-order Runge-Kutta scheme, using a $d t$ of 1 day. The values of $\mathbf{u}, T$, and $S$ at the particle location are determined via bilinear interpolation, and are taken as the average of the upper $20 \mathrm{~m}$. The $T / S$ value recorded along the trajectory is diagnostic only. A total of 121 particles are initialized a tenth of a degree apart (approximately Mercator's resolution) in a $1^{\circ} \times 1^{\circ}$ box around $8^{\circ} \mathrm{S}, 80^{\circ} \mathrm{E}$ and backtracked for 150 days. If the particle hits a land point, its last valid location is recorded as its final position (referred to as origin in main text). Note 
that vertical displacements are ignored, which should not be a significant issue for the time scale of interest here.

\section{REFERENCES}

Annamalai, H., R. Murtugudde, J. Potemra, S.-P. Xie, P. Liu, and B. Wang, 2003: Coupled dynamics over the Indian Ocean: Spring initiation of the zonal mode. Deep-Sea Res. II, 50, 23052330, https://doi.org/10.1016/S0967-0645(03)00058-4.

Argo, 2018: Argo float data and metadata from Global Data Assembly Centre (Argo GDAC). Accessed 2018, https://doi.org/ $10.17882 / 42182$.

Bonjean, F., and G. S. Lagerloef, 2002: Diagnostic model and analysis of the surface currents in the tropical Pacific Ocean. J. Phys. Oceanogr., 32, 2938-2954, https://doi.org/10.1175/ 1520-0485(2002)032<2938:DMAAOT>2.0.CO;2.

Bryan, F., and S. Bachman, 2015: Isohaline salinity budget of the North Atlantic salinity maximum. J. Phys. Oceanogr., 45, 724 736, https://doi.org/10.1175/JPO-D-14-0172.1.

Da-Allada, C. Y., F. Gaillard, and N. Kolodziejczyk, 2015: Mixedlayer salinity budget in the tropical Indian Ocean: Seasonal cycle based only on observations. Ocean Dyn., 65, 845-857, https://doi.org/10.1007/s10236-015-0837-7.

Dee, D. P., and Coauthors, 2011: The ERA-Interim reanalysis: Configuration and performance of the data assimilation system. Quart. J. Roy. Meteor. Soc., 137, 553-597, https://doi.org/10.1002/qj.828.

Du, Y., T. Qu, G. Meyers, Y. Masumoto, and H. Sasaki, 2005: Seasonal heat budget in the mixed layer of the southeastern tropical Indian Ocean in a high-resolution ocean general circulation model. J. Geophys. Res., 110, C04012, https://doi.org/ 10.1029/2004JC002845.

Durand, F., G. Alory, R. Dussin, and N. Reul, 2013: SMOS reveals the signature of Indian Ocean dipole events. Ocean Dyn., 63, 1203-1212, https://doi.org/10.1007/s10236-013-0660-y.

Earth Space Research, 2009: OSCAR third degree resolution ocean surface currents, version 1. PO.DAAC, accessed 20 January 2016, https://doi.org/10.5067/OSCAR-03D01.

Fairall, C. W., E. F. Bradley, J. E. Hare, A. A. Grachev, and J. B. Edson, 2003: Bulk parameterization of air-sea fluxes: Updates and verification for the COARE algorithm. J. Climate, 16, 571-591, https://doi.org/10.1175/1520-0442(2003)016<0571: BPOASF $>2.0 . \mathrm{CO} ; 2$.

Feng, M., and S. Wijffels, 2002: Intraseasonal variability in the South Equatorial Current of the east Indian Ocean. J. Phys. Oceanogr., 32, 265-277, https://doi.org/10.1175/1520-0485(2002)032<0265: IVITSE $>2.0 . \mathrm{CO} ; 2$

Foltz, G. R., J. Vialard, B. P. Kumar, and M. J. McPhaden, 2010: Seasonal mixed layer heat balance of the southwestern tropical Indian Ocean. J. Climate, 23, 947-965, https://doi.org/ 10.1175/2009JCLI3268.1.

Halkides, D. J., and T. Lee, 2009: Mechanisms controlling seasonalto-interannual mixed layer temperature variability in the southeastern tropical Indian Ocean. J. Geophys. Res., 114, C02012, https://doi.org/10.1029/2008JC004949.

_- and — 2011: Mechanisms controlling seasonal mixed layer temperature and salinity in the southwestern tropical Indian Ocean. Dyn. Atmos. Oceans, 51, 77-93, https://doi.org/ 10.1016/j.dynatmoce.2011.03.002.

Horii, T., I. Ueki, K. Ando, and K. Mizuno, 2013: Eastern Indian Ocean warming associated with the negative Indian Ocean dipole: A case study of the 2010 event. J. Geophys. Res. Oceans, 118, 536-549, https://doi.org/10.1002/jgrc.20071.
Huffman, G. J., and Coauthors, 2007: The TRMM Multisatellite Precipitation Analysis (TMPA): Quasi-global, multiyear, combined-sensor precipitation estimates at fine scales. J. Hydrometeor., 8, 38-55, https://doi.org/10.1175/JHM560.1.

Johnson, G. C., 2011: Deep signatures of southern tropical Indian Ocean annual Rossby waves. J. Phys. Oceanogr., 41, 19581964, https://doi.org/10.1175/JPO-D-11-029.1.

Kim, S.-B., I. Fukumori, and T. Lee, 2006: The closure of the ocean mixed layer temperature budget using level-coordinate model fields. J. Atmos. Oceanic Technol., 23, 840-853, https://doi.org/ 10.1175/JTECH1883.1.

, T. Lee, and I. Fukumori, 2007: Mechanisms controlling the interannual variation of mixed layer temperature averaged over the Niño-3 region. J. Climate, 20, 3822-3843, https://doi.org/ 10.1175/JCLI4206.1

Large, W. G., and S. G. Yeager, 2004: Diurnal to decadal global forcing for ocean and sea-ice models: The data sets and flux climatologies. NCAR Tech. Rep. NCAR/TN-460+STR, 105 pp., https://doi.org/10.5065/D6KK98Q6.

, and - 2009: The global climatology of an interannually varying air-sea flux data set. Climate Dyn., 33, 341-364, https:// doi.org/10.1007/s00382-008-0441-3.

- J. C. McWilliams, and S. C. Doney, 1994: Oceanic vertical mixing: A review and a model with a nonlocal boundary layer parameterization. Rev. Geophys., 32, 363-403, https://doi.org/ 10.1029/94RG01872.

Laurindo, L. C., A. J. Mariano, and R. Lumpkin, 2017: An improved near-surface velocity climatology for the global ocean from drifter observations. Deep-Sea Res. I, 124, 73-92, https:// doi.org/10.1016/j.dsr.2017.04.009.

Lebedev, K. V., S. DeCarlo, P. W. Hacker, N. A. Maximenko, J. T. Potemra, and Y. Shen, 2010a: Argo products at the Asia-Pacific Data Research Center. 2010 Fall Meeting, San Francisco, CA, Amer. Geophys. Union, Abstract IT25A-01.

$\longrightarrow,-,-,-$, , and,$- 2010 \mathrm{~b}$ : IPRC products based on Argo data. Accessed 20 January 2016, http://apdrc.soest. hawaii.edu/projects/argo/

Lee, T., I. Fukumori, and B. Tang, 2004: Temperature advection: Internal versus external processes. J. Phys. Oceanogr., 34, 1936-1944, https://doi.org/10.1175/1520-0485(2004)034<1936: TAIVEP $>2.0 . \mathrm{CO} ; 2$.

Masumoto, Y., and G. Meyers, 1998: Forced Rossby waves in the southern tropical Indian Ocean. J. Geophys. Res. Oceans, 103, 27 589-27 602, https://doi.org/10.1029/98JC02546.

McCreary, J. P., P. K. Kundu, and R. L. Molinari, 1993: A numerical investigation of dynamics, thermodynamics and mixed-layer processes in the Indian Ocean. Prog. Oceanogr., 31, 181-244, https://doi.org/10.1016/0079-6611(93)90002-U.

McPhaden, M. J., and Coauthors, 2009: RAMA: The Research Moored Array for African-Asian-Australian Monsoon Analysis and Prediction. Bull. Amer. Meteor. Soc., 90, 459-480, https://doi.org/10.1175/2008BAMS2608.1.

Menezes, V. V., M. L. Vianna, and H. E. Phillips, 2014: Aquarius sea surface salinity in the south Indian Ocean: Revealing annual-period planetary waves. J. Geophys. Res. Oceans, $\mathbf{1 1 9}$, 3883-3908, https://doi.org/10.1002/2014JC009935.

Moisan, J. R., and P. P. Niiler, 1998: The seasonal heat budget of the North Pacific: Net heat flux and heat storage rates (19501990). J. Phys. Oceanogr., 28, 401-421, https://doi.org/10.1175/ 1520-0485(1998)028<0401:TSHBOT $>2.0$. CO;2.

NOAA, 2016: Global Tropical Moored Buoy Array. Pacific Marine Environmental Laboratory, accessed 5 February 2016, https:// www.pmel.noaa.gov/tao/drupal/disdel/. 
_ 2018: A drifter-derived monthly climatology of global near-surface currents. NOAA/Drifter Data Assembly Center, accessed 10 June 2018, http://www.aoml.noaa.gov/phod/dac/dac_meanvel.php.

Ogata, T., S.-P. Xie, J. Lan, and X. Zheng, 2013: Importance of ocean dynamics for the skewness of the Indian Ocean dipole mode. $J$. Climate, 26, 2145-2159, https://doi.org/10.1175/JCLI-D-11-00615.1.

Périgaud, C., and P. Delecluse, 1992: Annual sea level variations in the southern tropical Indian Ocean from Geosat and shallowwater simulations. J. Geophys. Res. Oceans, 97 (C12), 20169 20 178, https://doi.org/10.1029/92JC01961.

Rossow, W. B., and R. A. Schiffer, 1999: Advances in understanding clouds from ISCCP. Bull. Amer. Meteor. Soc., 80, 2261-2287, https:// doi.org/10.1175/1520-0477(1999)080<2261:AIUCFI > 2.0.CO;2.

Saji, N., B. Goswami, P. Vinayachandran, and T. Yamagata, 1999: A dipole mode in the tropical Indian Ocean. Nature, 401, 360 363, https://doi.org/10.1038/43854.

Schott, F. A., S.-P. Xie, and J. P. McCreary, 2009: Indian Ocean circulation and climate variability. Rev. Geophys., 47, RG1002, https://doi.org/10.1029/2007RG000245.

Seiki, A., M. Katsumata, T. Horii, T. Hasegawa, K. J. Richards, K. Yoneyama, and R. Shirooka, 2013: Abrupt cooling associated with the oceanic Rossby wave and lateral advection during CINDY2011. J. Geophys. Res. Oceans, 118, 5523-5535, https://doi.org/10.1002/jgrc.20381.

Smith, R., and Coauthors, 2010: The Parallel Ocean Program (POP) Reference Manual Ocean Component of the Community Climate System Model (CCSM) and Community Earth System Model (CESM). Tech. Rep. LAUR-01853, Los Alamos National Laboratory, 140 pp., https://ccsm.ucar.edu/ models/cesm1.2/pop2/doc/sci/POPRefManual.pdf.

Stine, A. R., and P. Huybers, 2012: Changes in the seasonal cycle of temperature and atmospheric circulation. J. Climate, 25, 73627380, https://doi.org/10.1175/JCLI-D-11-00470.1.

Trenary, L. L., and W. Han, 2012: Intraseasonal-to-interannual variability of south Indian Ocean sea level and thermocline: Remote versus local forcing. J. Phys. Oceanogr., 42, 602-627, https://doi.org/10.1175/JPO-D-11-084.1.

TRMM, 2011: TRMM (TMPA/3B43) Rainfall Estimate L3 1 month 0.25 degree $\times 0.25$ degree V7. Goddard Earth Sci- ences Data and Information Services Center (GES DISC), accessed 20 January 2016, https://doi.org/10.5067/TRMM/ TMPA/MONTH/7.

Vialard, J., G. R. Foltz, M. J. McPhaden, J. P. Duvel, and C. de Boyer Montégut, 2008: Strong Indian Ocean sea surface temperature signals associated with the Madden-Julian oscillation in late 2007 and early 2008. Geophys. Res. Lett., 35, L19608, https://doi.org/10.1029/2008GL035238.

—, and Coauthors, 2009: Cirene: Air-sea interactions in the Seychelles-Chagos thermocline ridge region. Bull. Amer. Meteor. Soc., 90, 45-61, https://doi.org/10.1175/ 2008BAMS2499.1.

Webster, P. J., A. M. Moore, J. P. Loschnigg, and R. R. Leben, 1999: Coupled ocean-atmosphere dynamics in the Indian Ocean during 1997-98. Nature, 401, 356-360, https://doi.org/ $10.1038 / 43848$

Xie, S.-P., H. Annamalai, F. A. Schott, and J. P. McCreary Jr., 2002: Structure and mechanisms of south Indian Ocean climate variability. J. Climate, 15, 864-878, https://doi.org/10.1175/ 1520-0442(2002)015<0864:SAMOSI $>2.0 . \mathrm{CO} ; 2$.

Yokoi, T., T. Tozuka, and T. Yamagata, 2012: Seasonal and interannual variations of the SST above the Seychelles Dome. J. Climate, 25, 800-814, https://doi.org/10.1175/JCLI-D-10-05001.1.

Yoneyama, K., C. Zhang, and C. N. Long, 2013: Tracking pulses of the Madden-Julian oscillation. Bull. Amer. Meteor. Soc., 94, 1871-1891, https://doi.org/10.1175/BAMSD-12-00157.1.

Yu, L., X. Jin, and R. A. Weller, 2008: Multidecade global flux datasets from the Objectively Analyzed Air-Sea Fluxes (OAFlux) project: Latent and sensible heat fluxes, ocean evaporation, and related surface meteorological variables. OAFlux Project Tech. Rep. OA-2008-01, 64 pp., http://oaflux. whoi.edu/pdfs/OAFlux_TechReport_3rd_release.pdf.

Zhang, C., 2005: Madden-Julian oscillation. Rev. Geophys., 43, RG2003, https://doi.org/10.1029/2004RG000158.

Zhou, L., R. Murtugudde, and M. Jochum, 2008: Seasonal influence of Indonesian Throughflow in the southwestern Indian Ocean. J. Phys. Oceanogr., 38, 1529-1541, https://doi.org/ 10.1175/2007JPO3851.1. 